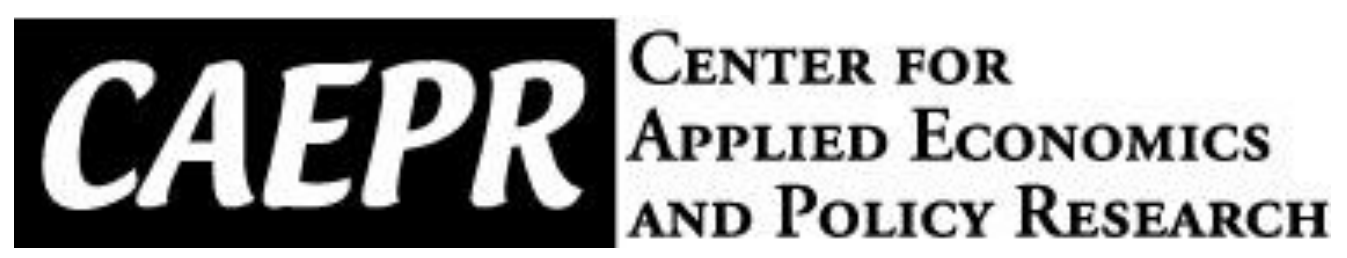

CAEPR Working Paper

\#2012-002

\title{
Time-Varying Oil Price Volatility and Macroeconomic Aggregates
}

\author{
Michael Plante \\ Federal Reserve Bank of Dallas \\ Nora Traum \\ North Carolina State University
}

February 11, 2012

This paper can be downloaded without charge from the Social Science Research Network electronic library at: http://ssrn.com/abstract=2005312.

The Center for Applied Economics and Policy Research resides in the Department of Economics at Indiana University Bloomington. CAEPR can be found on the Internet at: http://www.indiana.edu/ caepr. CAEPR can be reached via email at caepr@indiana.edu or via phone at 812-855-4050.

(C2012 by Michael Plante and Nora Traum. All rights reserved. Short sections of text, not to exceed two paragraphs, may be quoted without explicit permission provided that full credit, including $\odot$ notice, is given to the source. 


\title{
Time-Varying Oil Price Volatility and Macroeconomic Aggregates
}

\author{
Michael Plante and Nora Traum*
}

February 11, 2012

\begin{abstract}
We illustrate the theoretical relation among output, consumption, investment, and oil price volatility in a real business cycle model. The model incorporates demand for oil by a firm, as an intermediate input, and by a household, used in conjunction with a durable good. We estimate a stochastic volatility process for the real price of oil over the period 1986-2011 and utilize the estimated process in a non-linear approximation of the model. For realistic calibrations, an increase in oil price volatility produces a temporary decrease in durable spending, while precautionary savings motives lead investment and real GDP to rise. Irreversible capital and durable investment decisions do not overturn this result.
\end{abstract}

Keywords: DSGE model, energy, oil price, stochastic volatility

JEL Classifications: C32, E21, E22, Q43

*We thank Ron Alquist, Sebnem Kalemli-Ozcan, Junghoon Lee, James Murray, Barbara Rossi, and Todd Walker, as well as participants at Colorado College, the University of East Anglia, the 2011 EER Talented Economist Clinic, and the 2011 Midwest Economics Association Conference for helpful comments. Federal Reserve Bank of Dallas, michael.plante@dal.frb.edu; North Carolina State University, nora_traum@ncsu.edu. The views presented in this paper are those of the authors alone and do not reflect the official views of the Federal Reserve Bank of Dallas or the Federal Reserve System as a whole. 


\section{Introduction}

The majority of past research on oil prices has centered on the effects of price level changes, but recently a growing literature has focused on the consequences of oil price volatility. Empirically, several authors have found that increased oil price uncertainty may have a depressing effect on macroeconomic variables (Ferderer (1996), Guo and Kliesen (2005), and Elder and Serletis (2010)). In addition, results from partial equilibrium analysis suggest that rising oil price volatility dampens economic activity. ${ }^{1}$

Nevertheless, to the authors' knowledge, no rigorous investigation of the theoretical effects of changes in oil price volatility in general equilibrium exists. This paper seeks to fill this gap by illustrating the theoretical relation among output, consumption, investment, and oil price volatility in a real business cycle (RBC) model. The paper's core contribution is to discern the various transmission mechanisms of oil price volatility shocks and to determine a RBC model's ability to qualitatively match results from the empirical literature and partial equilibrium analysis.

We start with a RBC model that incorporates both firm demand for oil as an intermediate input and household demand for oil that is used in conjunction with a durable good. We estimate a stochastic volatility process for the real U.S. price of oil using Bayesian methods, similar to Fernandez-Villaverde, Guerron-Quintana, Rubio-Ramirez, and Uribe (2011), and use the estimated process in the model. The model is calibrated to match features of U.S. oil consumption and solved with a non-linear solution method. Impulse responses demonstrate how increases in uncertainty about future oil prices, measured as an increase in an oil price volatility shock, influence economic behavior.

Previous theoretical research has emphasized two main channels through which general uncertainty can affect economic decisions, with special emphasis on investment decisions. ${ }^{2}$ Since at least Sandmo (1970), it has been known that higher uncertainty can lead agents to consume less and save more, i.e. the precautionary savings motive (see Carroll and Kimball (2008) for a survey of the literature). This channel tends to increase investment. In contrast, the second channel can reduce investment through a real options effect when investment is irreversible (examples include Bernanke (1983) and Bloom (2009)).

By specifically modeling household and firm demand for oil along with oil price uncer-

\footnotetext{
${ }^{1}$ The investment under uncertainty literature is usually cited as an explanation for this result. See Bernanke (1983) and Pindyck (1991) for example.

${ }^{2}$ In addition, the literature discusses the Hartman-Abel effect, where higher uncertainty about prices (input costs or output prices) can increase perfectly competitive firms' demand for capital and investment (Hartman (1972), Abel (1983)). However, qualitatively the results depend upon assumptions about the firm's behavior and whether the shocks are to prices or quantities (see for example Caballero (1991)).
} 
tainty, we distinguish how the various transmission mechanisms apply distinctively to oil price volatility. In addition, the general equilibrium approach of our analysis provides a coherent framework to study simultaneously the different transmission mechanisms of oil price volatility shocks and to determine which effects dominate overall.

We find three key factors influence the qualitative responses to increased oil price uncertainty. First, the degree of consumption smoothing affects the strength of precautionary savings motives which encourage households to save more. Second, whether oil and durables are Edgeworth compliments or substitutes affects households' desires to accumulate durables following increases in oil price uncertainty. Similarly, the degree to which firms can substitute away from oil in production influences the marginal productivity of capital and labor, and, in turn, the response of investment. Depending upon the model calibration, we demonstrate that increases or decreases in investment spending, spending on durables, and real GDP are all possible following increases in oil price uncertainty.

For realistic calibrations of the model, however, we find that precautionary savings motives lead investment and GDP to rise following increased oil price uncertainty. The result is magnified by the inclusion of household demand for durable goods and oil, since households prefer to reduce durable spending and increase their savings.

Finally, we document that irreversible investment decisions do not necessarily overturn the results. Bernanke (1983) and Pindyck (1991) have shown in a partial equilibrium framework that oil price uncertainty is important for investment decisions when firms consider an irreversible investment. To the authors' knowledge, this paper is the first to focus specifically on the general equilibrium effects of oil price volatility shocks with irreversible investment. To explore this issue, we adopt a version of the Atkeson and Kehoe (1999) putty-clay model.

We introduce vintage specific, and hence irreversible, capital and durable goods. Each type of capital or durable good uses energy in a fixed proportion. In the face of heightened uncertainty, this adds a strong incentive to reduce investment, for both capital and durable goods, as higher uncertainty about the cost of oil encourages agents to reduce oil and capital/durable good usage simultaneously. In a model without durable investment, we find that this incentive overrides the precautionary savings motive, so that increased oil price volatility decreases capital investment and output. However, once putty-clay durables are introduced, increased oil price volatility leads durable investment to decline and capital investment to increase. In general equilibrium, the reduced spending on household durables encourages savings, and thus capital investment, to rise. This result highlights the importance of considering the various transmission channels and types of oil demand simultaneously.

Our work is related to a number of other areas of research. Several authors have found that in general equilibrium, irreversibility is important for macro aggregates following level 
shocks and increases in general uncertainty (Gilchrist and Williams (2005), Bloom, Bond, and Reenen (2007), and Bachmann, Caballero, and Engel (2010)), although these findings are not unchallenged (Veracierto (2002), Thomas (2002), and Khan and Thomas (2008)). More closely related, in models with irreversible investment, investment decreases in general equilibrium following oil price level shocks, as demonstrated by Atkeson and Kehoe (1999), Wei (2003), and Stockman (2006).

This paper is also related to an empirical literature that examines the effects of oil price uncertainty on macroeconomic aggregates. The results from this literature are mixed, depending upon the particular model specification and macroeconomic variables considered. Using a structural VAR, Ferderer (1996) finds that increased uncertainty leads to declines in industrial production. Both Guo and Kliesen (2005) and Elder and Serletis (2010) find that increased oil price volatility predicts lower industrial production. Guo and Kliesen (2005) finds that increased uncertainty forecasts lower nonresidential business fixed investment. Elder and Serletis (2010) finds that uncertainty dampens the mining component of private fixed investment, but has no statistically significant impact on private fixed investment net of mining. Kellogg (2010) finds that uncertainty has an important impact on drilling in the oil industry, leading credence to the result in Elder and Serletis (2010). The effects of oil price volatility on durable goods is mixed as well; Elder and Serletis (2010) find a negative effect on durables spending while Guo and Kliesen (2005) find no significant effect.

The paper is organized as follows. Section 2. introduces the model, and section 3. outlines our estimation of time-varying volatility for the U.S. real price of oil. Section 4. shows how model assumptions about preferences and technology influence the economy's responses to the oil price volatility shock. Section 5. presents results for an extension to incorporate irreversible investment decisions, and section 6. concludes.

\section{The Model}

The model economy is a real business cycle model that allows for capital accumulation, firm and household demand for oil products, and durable goods. The economy consists of a representative household and firm. Oil is imported from abroad at an exogenous world price. Trade is balanced each period, as oil imports are paid for with exports of domestic output.

The real world price of oil evolves according to a stochastic volatility model. ${ }^{3}$ Let $\hat{P}_{t}^{o}$ represent $\log$ deviations of the real price of oil from steady state. Then the oil price evolves

\footnotetext{
${ }^{3}$ This is consistent with Guo and Kliesen (2005), who finds that the volatility of the oil price is mainly driven by exogenous events such as terrorist attacks and conflicts in the Middle East.
} 
according to

$$
\begin{aligned}
\hat{P}_{t}^{o} & =\rho_{p} \hat{P}_{t-1}^{o}+\exp \left\{\eta_{t}^{p}\right\} \epsilon_{t} \\
\eta_{t}^{p} & =\left(1-\rho_{\eta^{p}}\right) \bar{\eta}^{p}+\rho_{\eta^{p}} \eta_{t-1}^{p}+\phi \zeta_{t}
\end{aligned}
$$

where both $\epsilon_{t}$ and $\zeta_{t}$ are normally distributed, uncorrelated shocks with mean zero and unit variance. $\epsilon_{t}$ shocks directly change the price level, while $\zeta_{t}$ shocks affect the spread of possible price changes and uncertainty about the oil price level.

\section{$2.1 \quad$ Production}

Final goods are produced by a representative firm operating under perfect competition. Firms use labor $L_{t}$, the capital stock $K_{t-1}$, and oil $O_{t}^{f}$ as inputs in production. Technology is given by

$$
Y_{t}=\left\{\left[\left(A_{t} L_{t}\right)^{\alpha}\left(K_{t-1}\right)^{1-\alpha}\right]^{\frac{\sigma-1}{\sigma}}+a_{1}\left(O_{t}^{f}\right)^{\frac{\sigma-1}{\sigma}}\right\}^{\frac{\sigma}{\sigma-1}} .
$$

where $\sigma>0$ is the elasticity of substitution between value-added output and oil, $\alpha \in(0,1)$ is the share of labor in value-added output, and $a_{1}>0$ is a distribution parameter. $A_{t}$ represents a productivity shock which evolves according to

$$
\ln A_{t}=\left(1-\rho_{a}\right) \ln \bar{A}+\rho_{a} \ln A_{t-1}+\exp \left\{\bar{\eta}^{a}\right\} \epsilon_{t}^{a},
$$

where $\epsilon_{t}^{a}$ is an i.i.d., mean zero shock with unit variance.

\subsection{Households}

Economic activity of the household is controlled by a representative agent. The agent derives utility from non-durable consumption $C_{t}$ and the service flow $S_{t}\left(D, O^{h}\right)$ of the pre-determined stock of durable consumption $D_{t-1}$ combined with household oil demand $O_{t}^{h} \cdot 4$ In addition, working hours $L_{t}$ provide disutility. Preferences are given by

$$
E_{0} \sum_{t=0}^{\infty} \beta^{t}\left\{\frac{\left[C_{t}^{\frac{\nu-1}{\nu}}+\kappa_{1} S_{t}\left(D, O^{h}\right)^{\frac{\nu-1}{\nu}}\right]^{\frac{1-\frac{1}{\tau}}{\nu}}}{1-\frac{1}{\tau}}-\kappa_{2} \frac{L_{t}^{1+\mu}}{1+\mu}\right\}
$$

\footnotetext{
${ }^{4}$ Loosely speaking, one can view household oil usage as general energy usage from oil inputs, such as gasoline, diesel, and heating oil.
} 
where

$$
S_{t}\left(D, O^{h}\right)=\left(D_{t-1}^{\frac{\xi-1}{\xi}}+\kappa_{3} O_{t}^{h \frac{\xi-1}{\xi}}\right)^{\frac{\xi}{\xi-1}} .
$$

$\beta \in(0,1)$ is the discount factor, $\tau>0$ is the intertemporal elasticity of substitution, $\mu>0$ the inverse Frisch elasticity of labor supply, and $\kappa_{1}, \kappa_{2}$, and $\kappa_{3}$ are distribution parameters. The elasticity of substitution between non-durable consumption and the service flow is $\nu>0$. $\xi>0$ denotes the elasticity of substitution between the stock of durable goods and household demand for oil products.

The agent receives wage income and capital rental income each period. Expenditures consist of non-durable and oil consumption and capital and durable investment. The agent's budget constraint is

$$
C_{t}+P_{t}^{o} O_{t}^{h}+I_{t}^{k}+I_{t}^{d}=W_{t} L_{t}+r_{t} K_{t-1},
$$

The durable good and the capital stock evolve according to

$$
\begin{aligned}
I_{t}^{d} & =D_{t}-\left(1-\delta_{d}\right) D_{t-1} \\
I_{t}^{k} & =K_{t}-\left(1-\delta_{k}\right) K_{t-1}+\frac{\phi_{k}}{2}\left(\frac{I_{t}^{k}}{K_{t-1}}-\delta_{k}\right)^{2} K_{t-1}
\end{aligned}
$$

where $\delta_{d}$ and $\delta_{k}$ are the depreciation rates for the durable good and the capital stock and $\frac{\phi_{k}}{2}\left(\frac{I_{t}^{k}}{K_{t-1}}-\delta_{k}\right)^{2}$ is an adjustment cost on investment, as in Pindyck and Rotemberg (1983).

\subsection{Aggregation}

The aggregate resource constraint is given by

$$
C_{t}+I_{t}^{k}+I_{t}^{d}+P_{t}^{o} O_{t}^{h}=Y_{t}-P_{t}^{o} O_{t}^{f}
$$

Value-added output $Y_{t}^{g}$ is equal to gross output minus expenditure on intermediate inputs

$$
Y_{t}^{g}=Y_{t}-P_{t}^{o} O_{t}^{f}
$$

\subsection{Calibration and Solution}

Table 2 lists the calibrated values assigned to parameters. We calibrate the model to a monthly frequency since we estimate oil price volatility with monthly data (see section 3 . for more details). The depreciation rates, $\delta_{d}$ and $\delta_{k}$, are set to 0.0083 , implying an annual rate of 10 percent. The discount factor, $\beta$, is set to 0.997 . We fix $\alpha$ so that labor income makes up 70 percent of value-added. 
We calibrate $\tau$ so that the intertemporal elasticity of substitution is 0.5 , well within the wide range of estimates in the literature (see Guvenen (2006)). We set $\mu$ so that the Frisch elasticity of labor supply is one. Both $\sigma$ and $\xi$ are set to 0.25 to match the low elasticities of demand that are usually found for oil products. ${ }^{5}$ The elasticity of substitution between non-durable consumption and durable services, $\nu$, is set to 0.50 . The capital adjustment cost parameter $\phi$ is set to 3 .

We calibrate $\kappa_{2}$ so that in the deterministic steady state households devote a third of their time to labor, $\bar{L}=0.33$. In addition, we fix the durable investment to GDP ratio and household and firm oil usage to GDP ratios to match the average values over the period 1986-2010 in the BEA's NIPA accounts. The distribution parameters $a_{1}, \kappa_{1}$, and $\kappa_{3}$ are chosen to match these ratios in steady state. Finally, we set the steady state oil price to one.

Due to our interest in the effects of stochastic volatility, we solve a third-order approximation of the model around the nonstochastic steady state. In the analysis in section 4 , we examine the effects of the volatility shock when the price level is held constant. Starting with third-order approximations there are non-zero coefficients attached to the stochastic volatility term independent of other shocks and variables in the model. ${ }^{6}$ The third-order solution, therefore, allows us to consider how a shock to the standard deviation independently affects macro aggregates. Since this can be done independently of the shock to the price level, the volatility shock demonstrates how pure uncertainty about the future oil price affects economic activity.

We use the method of Swanson, Anderson, and Levin (2005) and the authors' program PerturbationAIM to solve the model up to a third order approximation. For the calibrations considered, we have also considered a fourth order approximation and found the additional terms to have negligible impacts on the responses to an oil price volatility shock. ${ }^{7}$

\section{Measuring Oil Price Volatility}

In this section, we estimate the law of motion for the real price of oil assuming the oil price follows the stochastic volatility model given by equations (1) and (2).

We use U.S. monthly data ranging from 1986.1 to 2011.1 and calculate the real oil price

\footnotetext{
${ }^{5}$ Atkins and Jazayeri (2004) provides a summary of estimates for the demand for oil products. More recently, Arnberg and Bjorner (2007) and Hughes, Knittel, and Sperling (2008) estimate the compensated price elasticity of oil to be less than -0.8 .

${ }^{6}$ For discussion of this issue, see Fernandez-Villaverde, Guerron-Quintana, Rubio-Ramirez, and Uribe (2011). Building upon Schmitt-Grohe and Uribe (2004), a technical appendix available from the authors demonstrates why a third order approximation is necessary to analyze the independent effects of stochastic volatility shocks.

${ }^{7}$ Results are available from the authors upon request.
} 
by dividing the spot price of West Texas Intermediate oil by the core CPI. Standard tests for heteroscedasticity reject the null of homoscedastic shocks, giving evidence for time-varying volatility (see appendix 1.1).

Given the nonlinear structure of the stochastic volatility model, we use the sequential importance resampling particle filter to evaluate the likelihood function. ${ }^{8}$ In macroeconomics, a particle filter increasingly is used to estimate a stochastic volatility model (recent examples include Fernandez-Villaverde, Guerron-Quintana, Rubio-Ramirez, and Uribe (2011), Fernandez-Villaverde, Guerron-Quintana, Kuester, and Rubio-Ramirez (2011), and Born and Pfeifer (2011)). We use Bayesian methods and construct the posterior distribution of the oil process parameters using the random walk Metropolis-Hastings algorithm. ${ }^{9}$ See appendices 1.2 and 1.3 for more details.

Given the lack of guidance for the oil price process parameter values, we employ uniform priors that are a priori independent. The serial correlation parameters $\rho_{p}$ and $\rho_{\eta^{p}}$ are drawn from uniform priors on the unit interval. We let the average value of stochastic volatility $\left(\bar{\eta}^{p}\right)$ vary uniformly from -20 to 20 . The standard deviation of the volatility shock $\phi$ varies uniformly from 0 to 6 . The upper bound implies that, on average, the standard deviation of oil price innovations increases at most by an implausible factor of 400 following a positive stochastic volatility shock of one standard deviation.

Table 1 reports the priors along with the mean, median, and 5 and 95 percentiles from the posterior distributions. The shocks to the level and standard deviation of the oil price process are persistent. The mean estimated value of $\bar{\eta}^{p}$ implies that the oil price innovation has an average standard deviation of 0.065 . The mean estimated value of $\phi$ implies that a positive stochastic volatility shock of one standard deviation increases the standard deviation of the oil price innovation by a factor of 1.23 .

The estimates suggest that time-varying volatility is a relevant component of the historical oil price process. In what follows, we use the posterior medians from our estimated oil price process to calibrate the oil price process in our model.

\section{The Effects of Oil Price Uncertainty}

To gain insight about the various transmission mechanisms in the model, we examine the effects of increased oil price uncertainty in two simplified versions of the model. The first

\footnotetext{
${ }^{8}$ See Doucet, de Freitas, and Gordon (2001) and Fernandez-Villaverde, Guerron-Quintana, RubioRamirez, and Uribe (2011) for more details on the method. We use 10,000 particles for each evaluation of the likelihood.

${ }^{9}$ We sample 350,000 draws from the posterior distribution, discard the first 50,000 draws, thin every 5 draws, and perform diagnostic tests to ensure the convergence of the MCMC chain.
} 
case abstracts from durable goods and is a model where oil is used only for production. In contrast, the second case assumes that oil is used only in conjunction with the durable good. The two versions allow us to independently understand the firm-side and household-side demand effects of increased oil price uncertainty.

Since our focus is on the effects of oil price uncertainty, we consider a scenario where $\zeta_{t}$, the shock to the volatility of the oil price, is increased by one-standard deviation while holding fixed the level of the price of oil. In these experiments, agents continue to pay the same amount for oil but understand that future shocks to the oil price have a larger spread. We abstract from the effects of oil price level shocks, as their effects in similar DSGE models have already been considered. ${ }^{10}$

\subsection{Oil Price Uncertainty and Production}

Consider first a case which abstracts from durable goods and household demand for oil products. Per period utility is then given by

$$
U\left(C_{t}, L_{t}\right)=\frac{C_{t}^{1-\frac{1}{\tau}}}{1-\frac{1}{\tau}}-\kappa_{2} \frac{L_{t}^{1+\mu}}{1+\mu}
$$

and the agent's budget constraint by

$$
C_{t}+I_{t}^{k}=W_{t} L_{t}+r_{t} K_{t-1}
$$

The aggregate resource constraint is

$$
C_{t}+I_{t}^{k}=Y_{t}-P_{t}^{o} O_{t}^{f}
$$

All other features of the model remain the same.

In this case, there are two channels through which oil price uncertainty affects investment and, in turn, output and consumption. The first affects investment demand. Since oil prices are the cost for oil inputs, increased oil price uncertainty implies increased uncertainty for oil demand and, consequently, the marginal product of capital, given by

$$
Y_{t}^{\frac{1}{\sigma}}\left[\left(A_{t} L_{t}\right)^{\alpha}\left(K_{t-1}\right)^{1-\alpha}\right]^{\frac{\sigma-1}{\sigma}} K_{t-1}^{-1}=r_{t}
$$

This translates to larger uncertainty in the rental cost of capital, leading risk averse house-

\footnotetext{
${ }^{10}$ Examples include Jones, Leiby, and Paik (2004), Kilian (2008), Plante (2009), and Bodenstein, Erceg, and Guerrieri (2011).
} 
holds to decrease investment. On the other hand, larger oil price uncertainty increases income uncertainty (as wage and capital rental uncertainty rise), causing risk-averse consumers to increase precautionary savings and forego consumption to increase investment. In equilibrium, investment can rise or fall.

The general equilibrium results are driven by how easily oil can be substituted as an input in production (governed by $\sigma$ ) and by how willing households are to accept fluctuations in their consumption path (determined by $\tau$ ). One way the economy can deal with increases in oil price uncertainty is to reduce oil usage in production while the uncertainty is high. However, the ability to do so depends on the substitutability of inputs in production, i.e. $\sigma$. Households' desires to smooth consumption (determined by $\tau$ ) also matter, as this affects the strength of precautionary savings motives.

Figure 1 compares the responses of consumption spending, investment spending on the capital good, hours worked, and real GDP to a one-standard deviation shock to oil price volatility $\zeta_{t}$. We plot the log deviations of these variables from the stochastic steady state. The black solid lines are for the baseline calibration where $\sigma$ equals 0.25 and $\tau$ is set to 0.50 . The red dashed lines show the responses when $\sigma$ is set to 1.50, while the blue dotted-dashed lines correspond to responses when $\tau$ is set to 3 .

Figure 1 shows that the degree of substitutability between the inputs has important qualitative implications. When $\sigma$ is equal to 0.25 (black solid line), investment spending initially rises while consumption spending falls. The opposite result holds when $\sigma$ is equal to 1.50 (red dashed line), with investment spending falling and consumption rising initially. This result is driven by a subtle feature of the production function. Final goods are produced using value-added, i.e. capital and labor, as well as oil. The value of $\sigma$ sets the price elasticity of demand for oil (holding output fixed). It also controls the degree to which a rise in the price of oil affects the proportion of output that goes to oil vis-a-vis capital and labor. ${ }^{11}$ When $\sigma$ is low, it is difficult to substitute away from oil following an increase in its price, which increases the share of output that pays for oil. This necessarily reduces the share of output that goes to value-added. With increased oil price uncertainty, households attempt to insure themselves against this more likely event by increasing their savings. In contrast, when $\sigma$ is high, an increase in the oil price implies an increase in the share of output that goes to value-added. With increased oil price uncertainty, this leads households to decrease

\footnotetext{
${ }^{11}$ Note that $\sigma=\frac{\% \Delta\left(V A / O^{f}\right)}{\% \Delta M R T S}$ where MRTS is the marginal rate of technical substitution and $V A$ is value added. If $\sigma>1$, then a given percentage change in $P^{o} /\left(\right.$ Costs of VA) will raise the ratio $V A / O^{f}$ by a smaller percentage. Thus, the share of value added in total income would rise as the $V A / O^{f}$ ratio increased. When $\sigma<1$, the opposite occurs. An increase in the $V A / O^{f}$ ratio will lower value added's share. Note that in the limiting case $\sigma=0$, the production function is Leontief and increased oil price uncertainty can lead both oil usage and investment to decline.
} 
investment.

The intertemporal elasticity of substitution also is important for the qualitative responses. In the blue dotted-dashed scenario of figure $1, \sigma$ is low while $\tau$ is set to 4 , making the household very willing to accept fluctuations in its consumption path. In this case, investment falls and consumption rises, which is the opposite of the baseline calibration (the black solid line). Even with a low degree of substitutability between production inputs, large values of $\tau$ imply that households are more willing to substitute consumption across time. Precautionary savings motives are lower in this case, so the agent consumes more now, with certainty, at the expense of reduced investment spending. In contrast, when $\tau$ is relatively low, households have strong consumption smoothing motives. To buffer against the increased uncertainty, they save more. Households lower consumption today in order to guard against the potential of a (relatively) large negative shock in the future.

\subsection{Oil Price Uncertainty and Durable Goods}

Another channel through which changes in oil price uncertainty affect economic decisions is household consumption of oil. To understand how this channel works, we abstract now from oil in the production function and capital accumulation. In this case, the production function collapses to

$$
Y_{t}=A_{t} L_{t}
$$

and the resource constraint is given by

$$
Y_{t}=C_{t}+I_{t}^{d}+P_{t}^{o} O_{t}^{h}
$$

In this case, oil price volatility shocks impact the uncertainty surrounding the future costliness of household oil consumption and, in turn, the future costliness of the service flow of durables. The qualitative effects of increased oil price uncertainty are driven by the household's ability to substitute away from oil towards durables, and the ability to substitute away from services towards non-durable consumption. Substitutions of this sort allow the household to avoid some of the exposure to the (potentially) larger shocks that might occur in the future.

The degree of substitutability between the different consumption goods is governed by the relative values of the preference parameters $\tau, \nu$, and $\xi$. More specifically, these parameters determine whether or not the goods are Edgeworth compliments, substitutes, or independent 
goods. ${ }^{12}$ Appendix $\mathrm{C}$ shows that

$$
\begin{aligned}
\frac{U_{d o} O^{h}}{U_{d}} & =\frac{\gamma_{o}}{\sigma_{s}}-\frac{\gamma_{o}}{\nu}+\frac{\tau-\nu}{\nu \tau} \theta_{s} \\
\frac{U_{o d} D}{U_{o}} & =\frac{\gamma_{d}}{\xi}-\frac{\gamma_{d}}{\nu}+\frac{\tau-\nu}{\nu \tau} \theta_{s}
\end{aligned}
$$

where $\theta_{s}$ is the utility share provided by services $S$, and $\gamma_{d}$ and $\gamma_{o}$ are the shares of durables $D$ and oil $O^{h}$ in the production of services, respectively.

The complementarity of durables and oil depends upon the calibration of $\xi, \nu$, and $\tau$ jointly. A sufficient condition for Edgeworth complementarity is $\xi<\nu<\tau$. Likewise, durables and oil are substitutes if $\xi>\nu>\tau$ and are independent when $\xi=\nu=\tau$.

Figure 2 highlights the importance of the degree of substitutability. The baseline calibration (black solid line) sets both $\nu$ and $\tau$ equal to 0.50 and $\xi$ to 0.25 . The red dashed line corresponds to a calibration with $\tau$ equal to $0.75, \nu$ to 0.50 , and $\xi$ to 0.25 , which increases the complementarity between oil and durables relative to the baseline case. The blue dotted-dashed line sets $\tau$ to $0.25, \nu$ to 0.50 , and $\xi$ to 0.75 , making oil and durables Edgeworth substitutes

In the baseline calibration (black solid line), increases in oil price uncertainty cause decreases in durable spending and increases in non-durables consumption. The red dashed line scenario, which increases the complementarity between durables and oil, simply magnifies these effects. These results are driven by the complementarity between durables and oil. In this case, increases in oil price uncertainty cannot be offset by substituting out of oil products and towards spending on durables. Households respond to the greater price uncertainty by temporarily cutting back on durable spending. As there is no increase in the actual price of oil, this leaves the households with extra income which is spent on non-durable consumption.

The blue dotted-dashed line in the bottom portion of figure 2 gives an alternative scenario where durables and oil are substitutes for each other. ${ }^{13}$ In this case, households are temporarily able to reduce their exposure to some of the oil price uncertainty by foregoing non-durable consumption and increasing the stock of durables.

Finally, we consider how these results change when agents have another avenue for savings in the form of a capital good. We repeat the above experiments for an economy with capital accumulation and technology given by $Y_{t}=\left(A_{t} L_{t}\right)^{\alpha} K_{t-1}^{1-\alpha}$. Figure 3 displays the results. With a capital good available, an additional effect comes into play as households

\footnotetext{
${ }^{12}$ Technically, the following results hold exactly only when computing changes across deterministic steady states. However, the numerical results in figures 2 and 3 demonstrate they are key to determining the short-term effects as well.

${ }^{13}$ Although we have not modeled this explicitly, one could envision this as a situation where increased spending on fuel efficient cars allows one to substitute away from oil.
} 
can intertemporally substitute consumption by varying the capital stock. Although the additional savings channel does not qualitatively change the results, in all cases the capital and durable investment responses are inversely related.

\subsection{Oil Uncertainty in the Full Model}

So far we have considered versions of the model which have abstracted from either household demand or firm demand for oil products. This allowed us to understand how oil price uncertainty interacted with preferences and technology to lead to changes in consumption and investment decisions.

We now examine the effects of increased oil price uncertainty in the full model with both household and firm demand for oil. Figure 4 presents results for the baseline calibration given in table 2. Following increased oil price uncertainty, durable investment and consumption decline while capital investment and real GDP rise. Durable investment decreases due to the complementarity between durables and oil. Capital investment increases due to precautionary savings motives. In addition, compared to the results in the model without firm demand for oil (see figure 3), capital investment increases more. With firm demand for oil, there is increased uncertainty, as future wages and capital rental income are more volatile. This increases the precautionary savings motives of households and encourages capital investment to increase more.

The empirical literature and investment under uncertainty literature have typically found that increased oil price uncertainty reduces real GDP growth, investment in capital goods, and investment in durables. The results in figure 4 suggest that for realistic calibrations, a standard real business cycle (RBC) model is unable to match these findings. An important objection to the results so far is that we have abstracted from irreversible investment, which is often cited in the empirical literature as an explanation for heightened oil price uncertainty to depress the economy. We now turn towards this issue.

\section{Irreversible Investment}

So far, our models have allowed for smooth substitution between factors of production. We now introduce vintage specific, and hence irreversible, capital into the model by adopting a version of the Atkeson and Kehoe (1999) putty-clay model. We assume that there is a continuum of capital goods, each of which is characterized by an energy (oil) intensity $v$. Firms produce output using capital, oil, and labor inputs. Since different capital goods require a fixed energy intensity, existing capital goods use oil in the fixed proportion $1 / v$. 
Thus, in the short run there is no substitutability between capital and oil. However, firms can invest in new capital with a new energy intensity, making oil usage flexible over time. In the face of heightened oil price uncertainty, this adds a strong incentive to reduce investment, as higher uncertainty leads firms to reduce oil and capital usage simultaneously.

Since firms must purchase oil to use existing capital, more efficient energy types (those with a higher $v$ ) are more desirable. However, we assume that investing in more efficient capital is more expensive. $x(v)$ units of investment in capital of type $v$ combined with $1 / v$ units of oil produce capital services $x(v) v^{\varphi-1}$, where $\varphi<1 .^{14}$ Thus, when choosing a capital type, agents face a trade-off between minimizing energy costs and maximizing capital services. In addition, firms must decide whether or not to leave capital idle. Note that $x(v)$ units of capital combined with $e<x(v) / v$ units of oil leaves $x(v)-e v$ units of capital idle, since capital of type $v$ uses oil in the fixed proportion $1 / v$. Likewise, $x(v)$ units of capital combined with $e>x(v) / v$ units of oil wastes oil in the amount $e-x(v) / v$.

\subsection{No Durable Investment}

We first consider the implications of the putty-clay model without durable investment. In this case, the model is a simple extension of the Atkeson and Kehoe (1999) model to include a labor/leisure choice. Utility is given by

$$
E_{0} \sum_{t=0}^{\infty} \beta^{t}\left\{\frac{C_{t}^{1-\frac{1}{\tau}}}{1-\frac{1}{\tau}}-\kappa_{2} \frac{L_{t}^{1+\mu}}{1+\mu}\right\}
$$

Aggregate capital services are given by

$$
z_{t-1}=\int_{v} e_{t}(v) v^{\varphi} d v
$$

where $0 \leq e_{t}(v) \leq K_{t-1}(v) / v$ and investment in type $v$ capital evolves according to $x_{t}(v)=$ $K_{t}(v)-\left(1-\delta_{k}\right) K_{t-1}(v)$. Aggregate oil usage is given by

$$
O_{t-1}^{f}=\int_{v} e_{t}(v) d v
$$

Given the continuum of capital types, the putty-clay model poses a tractability problem. We solve the model following the procedure of Atkeson and Kehoe (1999). That is, we impose that (1) all types of existing capital are fully utilized and (2) investment at time $t$ occurs in

\footnotetext{
${ }^{14}$ We calibrate $\varphi=1-\alpha \frac{\bar{P}^{\circ} \bar{O}^{f}}{Y}$ so that the deterministic steady state firm oil usage to total output ratio is 0.02 .
} 
only one type of physical capital. ${ }^{15}$ Under these conditions, aggregate capital services and oil usage evolve according to

$$
\begin{aligned}
z_{t} & =\left(1-\delta_{k}\right) z_{t-1}+\frac{I_{t}^{k}}{v_{t}} v_{t}^{\varphi}, \\
O_{t}^{f} & =\left(1-\delta_{k}\right) O_{t-1}^{f}+\frac{I_{t}^{k}}{v_{t}},
\end{aligned}
$$

where $I_{t}^{k}$ is investment, $v_{t}$ is the chosen energy intensity in period $t, O_{t}^{f}$ is aggregate oil usage for production, and $z_{t}$ is aggregate capital services. Gross output is given by $Y_{t}=A_{t} L_{t}^{\alpha} z_{t-1}^{1-\alpha}$.

Figure 5 displays the impulse responses from the model following a one standard deviation increase in the oil price volatility shock. The black solid line is when the inverse intertemporal elasticity of substitution $\tau$ is 0.5 . The red dashed line is when $\tau=3$ and the blue dotteddashed line when $\tau=0.2$.

In all cases, an increase in oil price uncertainty leads to a decrease in investment, oil usage, and capital services, as the greater uncertainty about the input cost of oil discourages oil, and in turn capital, usage. As a result, the marginal product of labor declines, causing hours worked and output to fall. Consumption rises as agents are willing to increase consumption to forego current investment. As demonstrated in figure 5, the more agents care about consumption smoothing, the smaller the initial declines in investment and increases in consumption.

The results highlight the potential importance of considering irreversible investment. In the previous section where capital and oil were substitutable in the short run, precautionary savings motives led to an increase in savings, and therefore investment spending. Here, these motives are overturned.

\subsection{Durable Investment}

We now introduce into our putty-clay capital model a continuum of durable goods, each of which is characterized by its energy intensity $v^{d}$. Putty-clay durables are analogous to putt-clay capital goods. Existing durable goods use oil in the fixed proportion $1 / v^{d}$. Thus, in the short run durables and oil cannot be substituted. However, investment can occur in new durables with a new energy intensity, making durable oil usage elastic over time. This putty-clay specification has been used to model gasoline usage and the demand for cars with different fuel efficiencies (for example, Wei (2009)). Households prefer more efficient energy types (a higher $v^{d}$ ) to reduce costs of oil. However, investing in more efficient durables is

\footnotetext{
${ }^{15}$ Appendix 2.2 shows that these conditions are satisfied by the original problem for our calibrations over a large support of the shocks.
} 
more expensive. $x\left(v^{d}\right)$ units of investment in durable type $v^{d}$ combined with $1 / v^{d}$ units of oil produce durable services $x\left(v^{d}\right)^{\varphi_{d}-1}$, where $\varphi_{d}<1$.

The household's problem is now to maximize

$$
E_{0} \sum_{t=0}^{\infty} \beta^{t}\left\{\frac{\left[C_{t}^{\frac{\nu-1}{\nu}}+\kappa_{1}\left[\int_{v} e_{t}^{h}\left(v^{d}\right)\left(v^{d}\right)^{\varphi^{d}} d v^{d}\right]^{\frac{\nu-1}{\nu}}\right]^{\frac{1-\frac{1}{\tau}}{\nu-1}}}{1-\frac{1}{\tau}}-\kappa_{2} \frac{L_{t}^{1+\mu}}{1+\mu}\right\}
$$

where household oil usage $e_{t}^{h}\left(v^{d}\right)$ satisfies $0 \leq e_{t}^{h}\left(v^{d}\right) \leq d_{t-1}\left(v^{d}\right) / v^{d}$ and investment in type $v^{d}$ durables evolves according to $i_{t}^{d}\left(v^{d}\right)=d_{t}\left(v^{d}\right)-\left(1-\delta_{d}\right) d_{t-1}\left(v^{d}\right)$.

We impose the conditions that installed durables always are fully utilized and durable investment occurs in one specific energy type. ${ }^{16}$ Under these conditions, the aggregate stock of durable services and household oil demand evolve according to

$$
\begin{aligned}
D_{t} & =\left(1-\delta_{d}\right) D_{t-1}+\frac{I_{t}^{d}}{v_{t}^{d}}\left(v_{t}^{d}\right)^{\varphi} \\
O_{t}^{h} & =\left(1-\delta_{d}\right) O_{t-1}^{h}+\frac{I_{t}^{d}}{v_{t}^{d}}
\end{aligned}
$$

where $I_{t}^{d}$ is aggregate durable investment, $v_{t}^{d}$ is the energy intensity, $O_{t}^{h}$ is aggregate oil usage for durables, and $D_{t}$ is aggregate durable services. We calibrate $\varphi^{d}$ so that the deterministic steady state household oil usage to total output ratio is 0.05 . Figure 6 displays the impulse responses following a one standard deviation increase in the oil price volatility shock. The black solid line is when the inverse intertemporal elasticity of substitution $\tau$ is 0.5 . The red dashed line is when $\tau=3$, and the blue dotted-dashed line when $\tau=0.2$.

An increase in oil price uncertainty leads to a decrease in durables, and an increase in capital investment and capital services. Greater uncertainty about the price of oil leads households to decrease durable investment and durable services. Although greater uncertainty about input costs encourages capital investment and capital services to decline, precautionary savings motives still encourage households to increase savings. In equilibrium, the savings motive leads capital investment to increase, with investment occuring in more energy efficient capital. The increase in capital investment and capital services leads GDP to increase over most horizons as well.

These results highlight the trade-offs in general equilibrium posed by standard real busi-

\footnotetext{
${ }^{16}$ Appendix 2.3 shows that these conditions are satisfied by the original problem for our calibrations over a large support of the shocks.
} 
ness cycle models. Although the irreversible investment model discourages investment with higher oil price uncertainty, precautionary savings motives keep households from decreasing both durable and capital investment. Since oil usage by households is the predominant source of oil usage in the economy, durable investment declines and strengthens motives to increase capital investment.

\section{Conclusion}

We investigate the relationships among output, consumption, investment, and oil price volatility in a real business cycle model. The model framework incorporates both household and firm demand for oil, as well as the importance of irreversible investment in capital and durable goods. Realistic calibrations produce positive responses in investment spending and real GDP following increased oil price uncertainty. These responses mainly are driven by precautionary savings motives.

We show that while it is theoretically possible for durable spending to either rise or fall in the face of greater oil price uncertainty, for plausible calibrations durable spending tends to decrease. This magnifies the increase in investment spending, since the temporary reduction in durable spending allows households to increase their savings. If the elasticity of substitution between durables and oil is unrealistically high, it is possible for durable spending to increase and capital investment to decline.

Irreversible capital and durable investment decisions do not overturn the general results. Although the putty-clay framework creates a strong incentive to temporarily reduce both investment and durable spending, precautionary savings motives still encourage households to save. Taken together, the end result is reduced durable spending, which brings about increased savings, and, in turn, investment spending. These results highlight the importance of considering jointly firm and household demand for oil in order to understand how uncertainty about oil prices is transmitted throughout the economy.

While this paper gives insight into the role of oil price uncertainty, important issues remain. What are the underlying sources that cause stochastic volatility to appear in the data? As shown in Kilian (2009), the responses of macroeconomic variables to an increase in the oil price level vary with the source of the oil price level shock. It is plausible that different sources of oil price uncertainty might lead to different effects as well. Thus, formally modeling the driving force behind oil price volatility could be an insightful development. 


\begin{tabular}{llc} 
Value & Description & Calibration \\
\hline$\tau$ & Intertemporal Elasticity of Substitution & 0.5 \\
$\mu$ & Inverse Frisch Elasticity of Labor Supply & 1 \\
$\nu$ & Elasticity of Substitution between $C$ and $S$ & 0.50 \\
$\xi$ & Elasticity of Substitution between $O^{h}$ and $D$ & 0.25 \\
$\beta$ & Discount Factor & 0.997 \\
$\sigma$ & Elasticity of Substitution in Production & 0.25 \\
$\phi_{k}$ & Capital adjustment cost & 3 \\
$\alpha$ & Share of Labor Income in Real GDP & 0.70 \\
$\bar{L}$ & Steady State Time to Labor & 0.33 \\
$\delta_{d}$ & Depreciation of durables & 0.0083 \\
$\delta_{k}$ & Depreciation of capital & 0.0083 \\
$\frac{\bar{I}^{d}}{\bar{Y}^{g}}$ & Durable Investment to Value-Added ratio & 0.10 \\
$\frac{P^{o} \bar{O}^{h}}{\bar{Y}^{g}}$ & Household Oil Consumption to Value-Added ratio & 0.05 \\
$\frac{\bar{P}^{o} \bar{O}^{f}}{\bar{Y}^{g}}$ & Firm Oil Consumption to Value-Added ratio & 0.02 \\
$\bar{P}^{o}$ & Steady State Oil Price & 1 \\
$\bar{A}$ & Steady State Technology & 1
\end{tabular}

Table 1: Calibration for Benchmark Model.

\begin{tabular}{cc|c|ccc}
\multicolumn{2}{c}{ Parameter } & \multicolumn{2}{c}{ Prior } & \multicolumn{3}{c}{ Posterior } \\
Name & Domain & & Mean & Median & $95 \%$ CI \\
\hline$\rho_{\eta^{p}}$ & $\mathbf{R}^{+}$ & Uniform(0,1) & 0.78 & 0.81 & $(0.60,0.92)$ \\
$\rho_{p}$ & $\mathbf{R}^{+}$ & Uniform(0,1) & 0.89 & 0.89 & $(0.84,0.93)$ \\
$\bar{\eta}^{p}$ & $\mathbf{R}$ & Uniform(-20,20) & -2.73 & -2.74 & $(-2.88,-2.60)$ \\
$\phi$ & $\mathbf{R}^{+}$ & Uniform(0,6) & 0.21 & 0.21 & $(0.14,0.31)$
\end{tabular}

Table 2: Prior and Posterior Distributions for the Estimated Parameters. Reports the posterior mean, median, and $90 \%$ credible interval. 

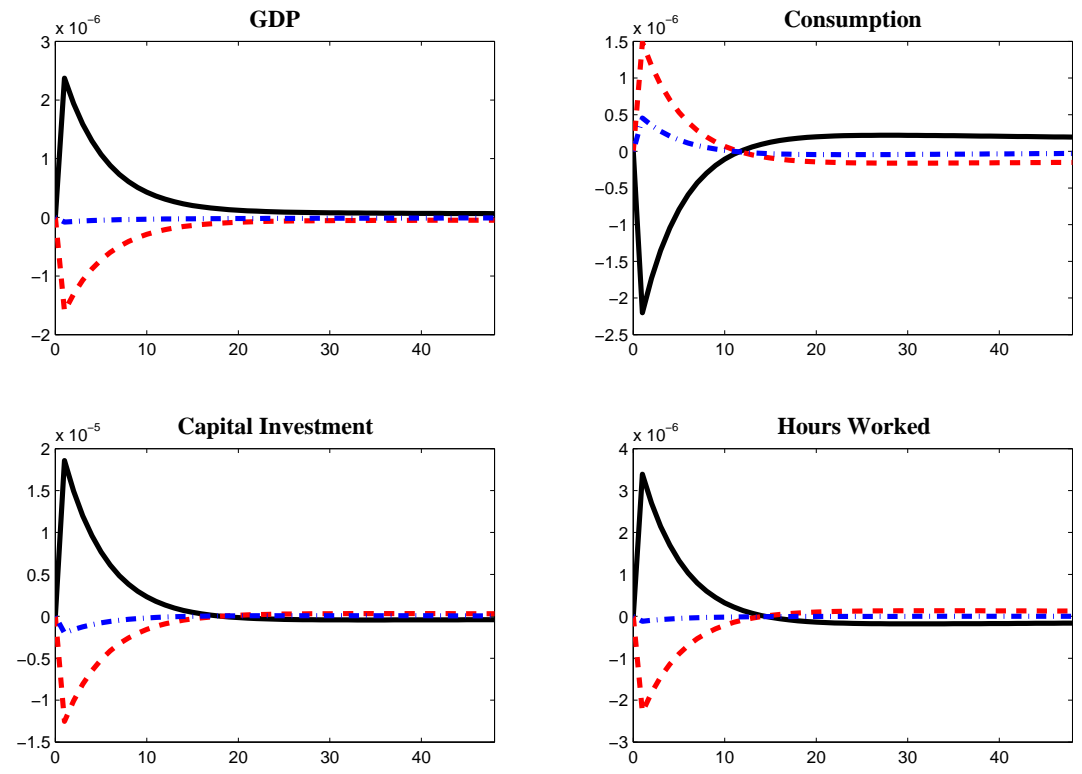

Figure 1: Impulse responses to a one standard deviation increase in the oil price volatility shock for the model where oil is used only in production of final goods. Black solid lines: $\sigma=0.25$ and $\tau=0.5$; red dashed lines: $\sigma=1.50$ and $\tau=0.5$; blue dotted-dashed lines: $\sigma=0.25$ and $\tau=3$. The x-axis measures months after a shock; the y-axis gives percentage deviations from the stochastic steady state. 

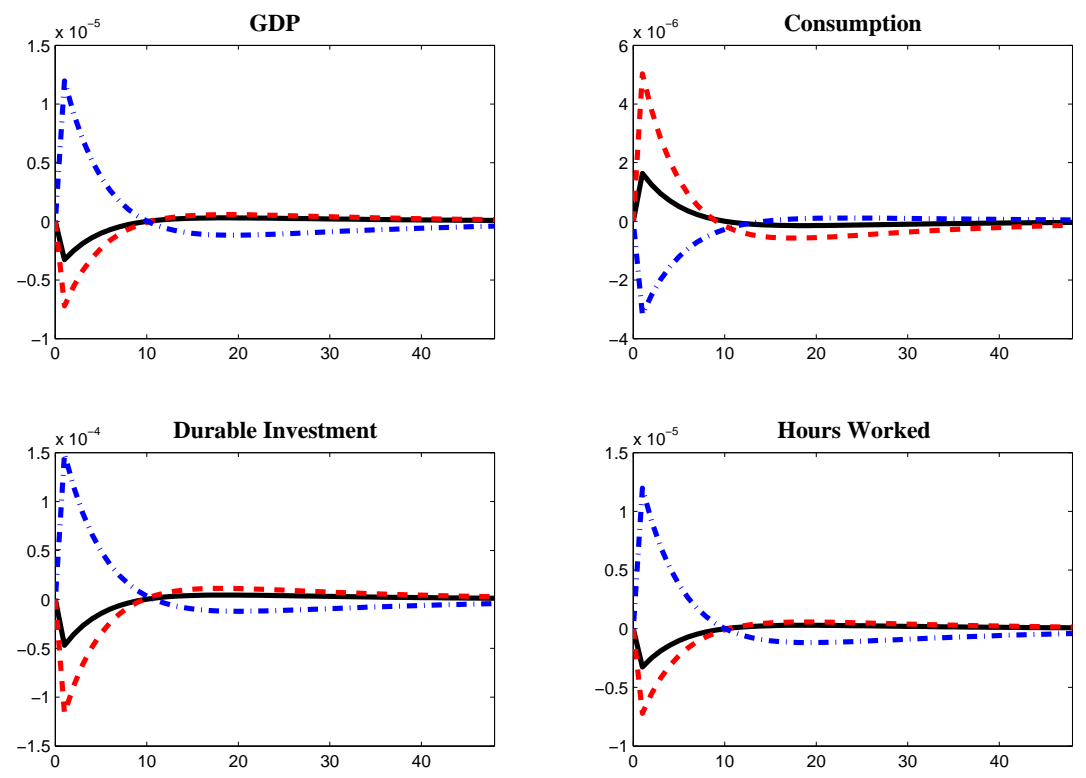

Figure 2: Impulse responses to a one standard deviation increase in the oil price volatility shock for the model with no firm demand for oil or capital in production. Black solid lines: $\tau=0.5, \nu=0.50, \xi=0.25$; red dashed lines: $\tau=0.75, \nu=0.50, \xi=0.25$; blue dotteddashed lines: $\tau=0.25, \nu=0.50, \xi=0.75$. The x-axis measures months after a shock; the $\mathrm{y}$-axis gives percentage deviations from the stochastic steady state. 

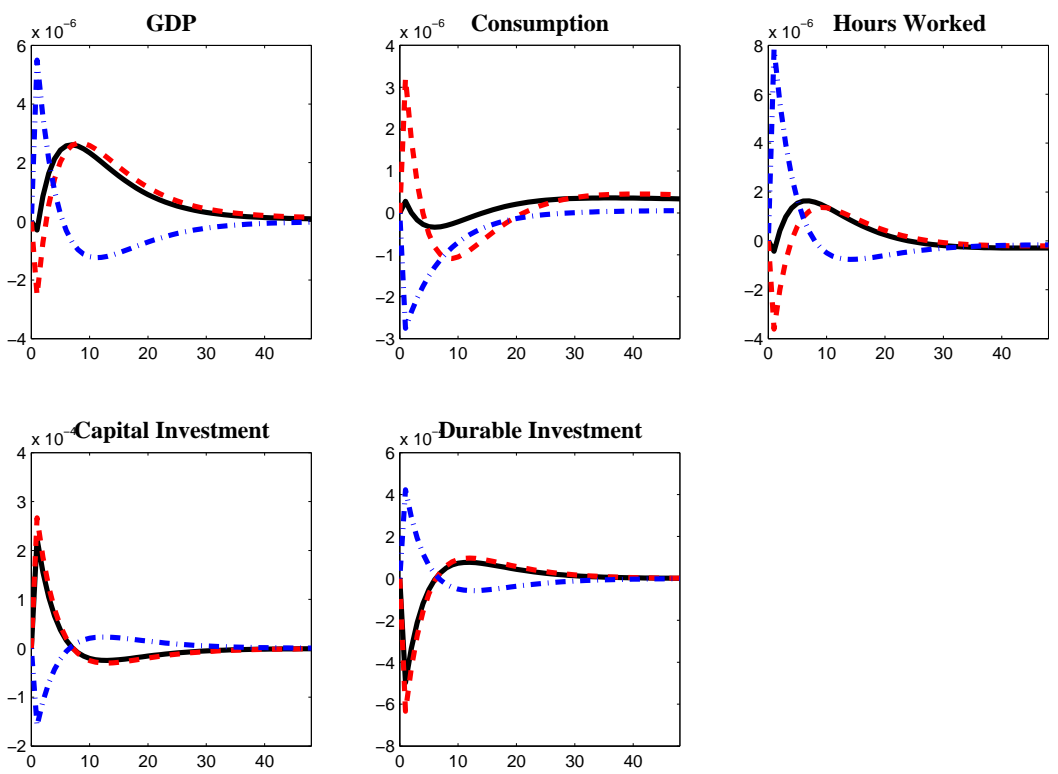

Figure 3: Impulse responses to a one standard deviation increase in the oil price volatility shock for the model with no firm demand for oil. Black solid lines: $\tau=0.5, \nu=0.50$, $\xi=0.25$; red dashed lines: $\tau=0.75, \nu=0.50, \xi=0.25$; blue dotted-dashed lines: $\tau=0.25$, $\nu=0.50, \xi=0.75$. The $\mathrm{x}$-axis measures months after a shock; the y-axis gives percentage deviations from the stochastic steady state. 

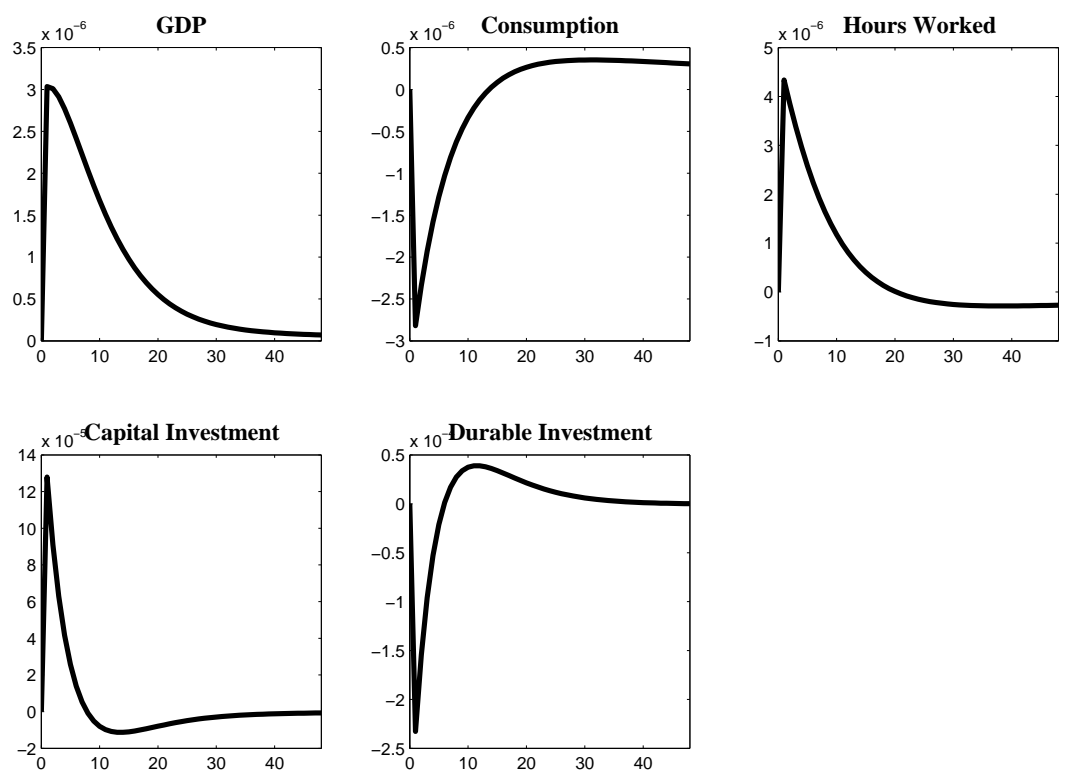

Figure 4: Impulse responses to a one standard deviation increase in the oil price volatility shock for the model with both household and firm demand for oil. The x-axis measures months after a shock; the y-axis gives percentage deviations from the stochastic steady state.
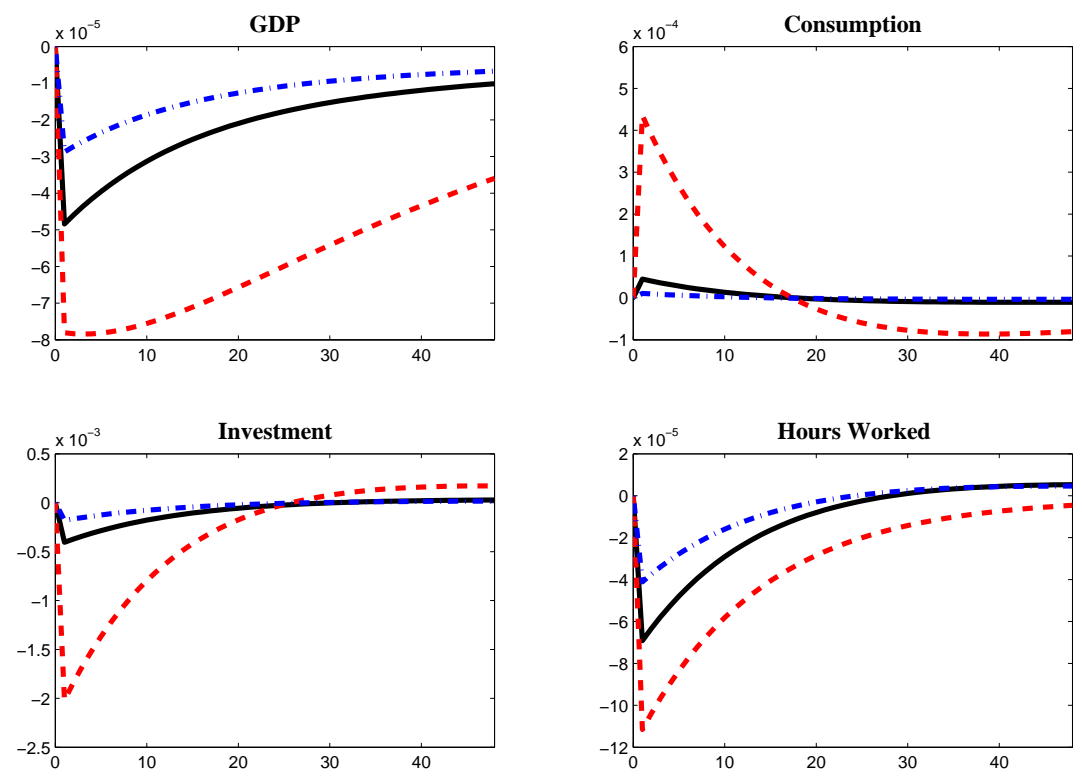

Figure 5: Impulse responses to a one standard deviation increase in the oil price volatility shock for the capital investment putty-clay model. Black solid line: $\tau=0.5$; red dashed line: $\tau=3$; blue dotted-dashed line: $\tau=0.2$. The x-axis measures months after a shock; the $\mathrm{y}$-axis gives percentage deviations from the stochastic steady state. 

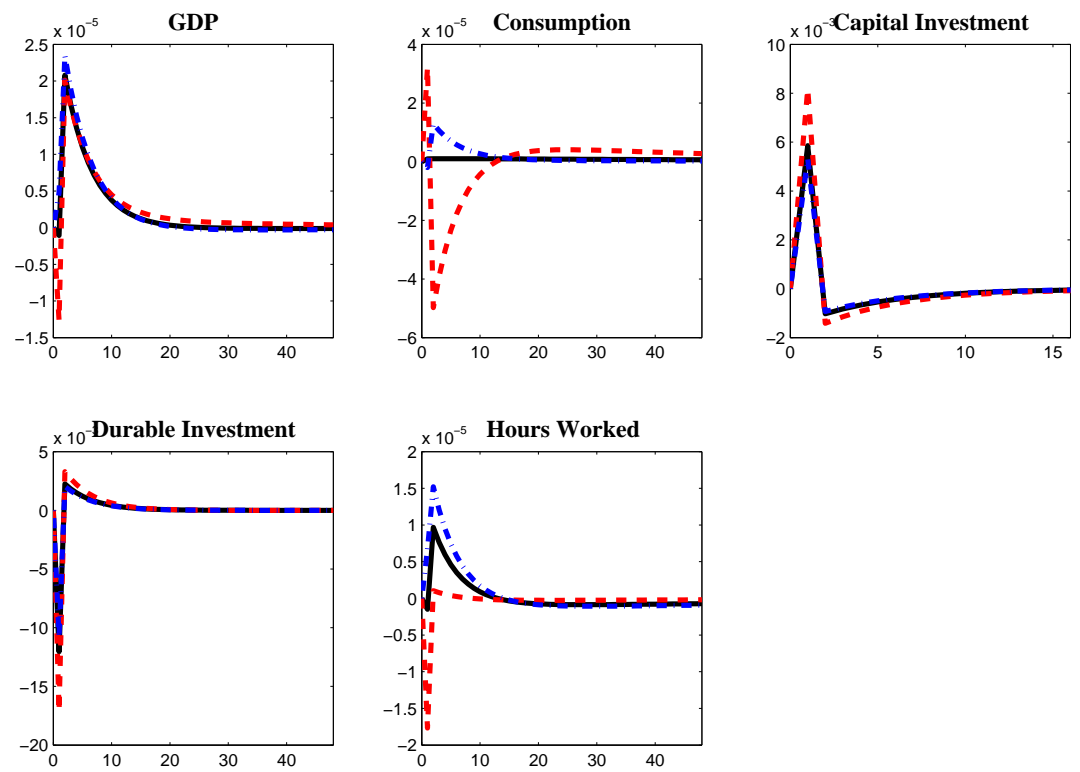

Figure 6: Impulse responses to a one standard deviation increase in the oil price volatility shock for the durable good and capital investment putty-clay model. Black solid line: $\tau=$ 0.5; red dashed line: $\tau=3$; blue dotted-dashed line: $\tau=0.2$. The $\mathrm{x}$-axis measures months after a shock; the $\mathrm{y}$-axis gives percentage deviations from the stochastic steady state. 


\begin{tabular}{ll} 
Test & p-value \\
\hline White (1980) & 0.00037 \\
Wooldridge (1990) & 0.00037 \\
Breusch and Pagan (1979)-Koenker (1981) & 0.0028
\end{tabular}

Table 3: Tests for heteroscedasticity.

\section{A Data \& Estimation}

\section{$1.1 \quad$ Data}

We use U.S. monthly data ranging from 1986.1 to 2011.1 and calculate the real oil price by dividing the spot price of West Texas Intermediate oil by the core CPI. All data is from the HAVER database. We take logs and demean our oil price series and apply a one-sided HP filter (see Stock and Watson (1999)). ${ }^{17}$ Prior to estimating the stochastic volatility model, we perform simple tests for heteroscedasticity. Table 3 presents p-values from the White (1980) test, the Wooldridge (1990) test, and the Breusch and Pagan (1979)-Koenker (1981) test. All three tests reject the null of homoscedasticity at the $1 \%$ level.

\subsection{Particle Filter Algorithm}

Let $p^{T}$ denote $\left\{\hat{P}_{t}^{o}\right\}_{t=1}^{T}$, which evolves according to equations 1 and 2 in the text. To evaluate the likelihood function $L\left(p^{T}\right)$, we use a sequential Monte Carlo filter. The algorithm is as follows:

- Step 1. Initialize the state variable $\eta_{0}^{p}$ by generating 10,000 values for $\eta_{0}^{p}$ from $\eta^{p}$ 's unconditional distribution, $\mathrm{N}\left(\bar{\eta}^{p}, \frac{\left(\bar{\eta}^{p}\right)^{2}}{1-\rho_{\eta}^{2}}\right)$. Denote these particles by $\eta_{0}^{i}$. Draw 10,000 values from $\mathrm{N}(0,1)$ and call each $\zeta^{1 \mid 0, i}$. By induction, in period $t$ these are particles $\zeta^{t \mid t-1, i}$.

- Step 2. Construct $\eta^{t \mid t-1, i}$ using equation 2 in the text. Assign to each draw $\left(\zeta^{t \mid t-1, i}\right.$, $\left.\eta^{t \mid t-1, i}\right)$ a weight defined as:

$$
w_{t}^{i}=\frac{1}{(2 \pi)^{0.5}} \exp \left[-\frac{1}{2}\left(\frac{\hat{P}_{t}^{o}-\rho_{p} \hat{P}_{t-1}^{o}}{\exp \left(\eta^{t \mid t-1, i}\right)}\right)^{2}\right]
$$

\footnotetext{
${ }^{17}$ Some suggest the real price of oil is stationary (for example, Kilian (2009)). Given the high persistence in the price level, it is difficult for unit root tests to be conclusive. Since the oil price level is unaltered in the experiments in the text, this issue is of lesser importance for our results. When using the unfiltered oil price process, the median and [5\% 95\%] parameter estimates from the posterior distribution become: (1) $\rho_{\eta^{p}}: 0.53,[0.37,0.59] ;(2) \rho_{p}: 0.97,[0.96,0.97] ;(3) \bar{\eta}^{p}:-2.89,[-3.07,-2.84] ;$ and $(4) \phi: 0.09,[0.08,0.10]$.
} 
- Step 3. Normalize the weights:

$$
\tilde{w}_{t}^{i}=\frac{w_{t}^{i}}{\sum_{i=1}^{N} w_{t}^{i}}
$$

Update the values of $\eta^{t \mid t-1, i}$ by sampling with replacement 10,000 values of $\eta^{t \mid t-1, i}$ using the relative weights $\tilde{w}_{t}^{i}$ and the stratified resampling algorithm.

- Repeat steps 2-3 for $t \leq T$.

The likelihood function is approximated by

$$
\begin{aligned}
& L\left(p^{T}\right) \simeq \\
& \left(\frac{1}{N} \sum_{i=1}^{N} \frac{1}{(2 \pi)^{0.5}} \exp \left[-\frac{1}{2}\left(\frac{\hat{P}_{1}^{o}-\rho_{p} \hat{P}_{0}^{o}}{\exp \left(\eta_{0}^{i}\right)}\right)^{2}\right]\right)\left(\prod_{t=2}^{T} \frac{1}{N} \sum_{i=1}^{N} \frac{1}{(2 \pi)^{0.5}} \exp \left[-\frac{1}{2}\left(\frac{\hat{P}_{t}^{o}-\rho_{p} \hat{P}_{t-1}^{o}}{\exp \left(\eta^{t \mid t-1, i}\right)}\right)^{2}\right]\right)
\end{aligned}
$$

\subsection{MCMC Algorithm}

The random walk Metropolis-Hastings algorithm used for the estimation works as follows:

- Step 1. Compute the posterior log-likelihood for 500 draws from the priors. Call the draw with the highest posterior log-likelihood value $\theta^{*}$.

- Step 2. Starting from $\theta^{*}$, generate a MCMC chain using the following random-walk proposal density

$$
\theta_{j+1}^{\text {prop }}=\theta_{j}^{\text {prop }}+c \mathcal{N}(0, \Sigma), \quad j=1, \ldots, 100,000
$$

where $\Sigma$ is the covariance matrix of 5,000 draws from the priors and $c>0$ is a tuning parameter set to determine the acceptance ratio.

- Step 3. Compute the acceptance ratio $\varphi=\min \left\{\frac{p\left(\theta_{j+1}^{p r o p} \mid p^{T}\right)}{p\left(\theta_{j} \mid p^{T}\right)}, 1\right\}$. Let $u$ be a drawn from a uniform distribution over the unit interval. Then $\theta_{j+1}=\theta_{j+1}^{\text {prop }}$ if $u<\varphi$ and $\theta_{j+1}=\theta_{j}$ otherwise. Repeat for $j=1, \ldots, 100,000$.

- Step 4. Update the random walk proposal density in the following way. Update $\Sigma$ to be the covariance matrix from the previous draws $\left\{\theta_{j}\right\}_{1}^{100,000}$. Update $\theta^{*}$ to be the mean of previous draws $\left\{\theta_{j}\right\}_{1}^{100,000}$. Starting from the new $\theta^{*}$, proceed through steps 2 and 3 for 350,000 draws from the new MCMC chain.

We burn the first 50,000 draws from the final MCMC chain and thin every 5 draws. The final acceptance rate is 0.37 . Figure 7 gives the smoothed estimates of $\eta$, our measure of 


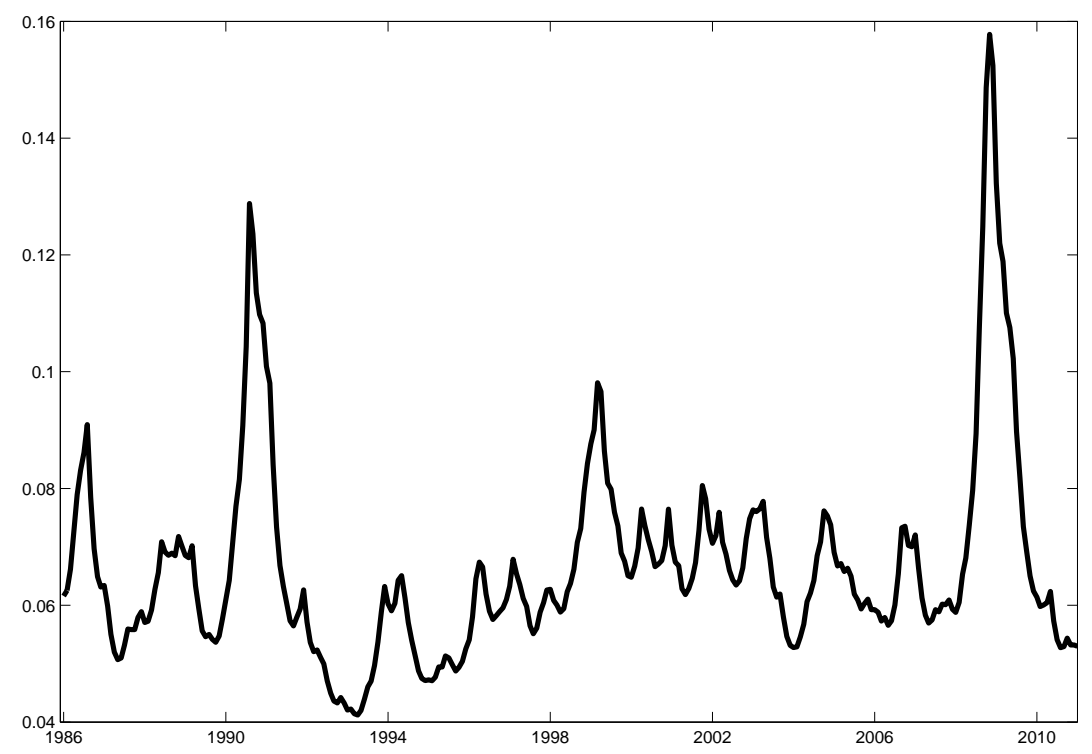

Figure 7: Smoothed estimates of the time-varying volatility of the oil price $\left(\exp \eta_{t}^{p}\right)$, constructed from the posterior mode.

time-varying volatility, using the posterior mode parameters and the sequential monte carlo approximation of the forward-backward smoothing recursion. 


\section{B Model Solutions}

\subsection{Benchmark Model}

The equilibrium conditions for the benchmark model are

$$
\begin{aligned}
\lambda_{t} & =\left[C_{t}^{b}+\kappa_{1} S_{t}^{b}\right]^{\frac{w}{b}-1} C_{t}^{b-1}, \\
P_{t}^{o} \lambda_{t} & =\left[C_{t}^{b}+\kappa_{1} S_{t}^{b}\right]^{\frac{w}{b}-1} \kappa_{1} S_{t}^{\frac{1}{\xi}-\frac{1}{\nu}} \kappa_{3} O_{t}^{h^{-\frac{1}{\xi}}}, \\
\lambda_{t} & =\beta E_{t}\left\{\lambda_{t+1}\left(1-\delta_{d}\right)+\left[C_{t+1}^{b}+\kappa_{1} S_{t+1}\right]^{\frac{w}{b}-1} \kappa_{1} S_{t+1}^{\frac{1}{\xi}-\frac{1}{\nu}} D_{t}^{-\frac{1}{\xi}}\right\} \\
\lambda_{t} W_{t} & =\kappa_{2} L_{t}^{\mu}, \\
\lambda_{t}^{k} & =\beta E_{t}\left(\frac{\lambda_{t+1}}{\lambda_{t}}\right)\left\{r_{t+1}+\lambda_{t+1}^{k}\left[\left(1-\delta_{k}\right)-\frac{\phi_{k}}{2}\left(\frac{I_{t+1}^{k}}{K_{t}}-\delta_{k}\right)^{2}+\phi_{k}\left(\frac{I_{t+1}^{k}}{K_{t}}-\delta_{k}\right) \frac{I_{t+1}^{k}}{K_{t}}\right]\right\}, \\
I_{t}^{d} & =D_{t}-\left(1-\delta_{d}\right) D_{t-1}, \\
I_{t}^{k} & =K_{t}-\left(1-\delta_{k}\right) K_{t-1}+\frac{\phi_{k}}{2}\left(\frac{I_{t}^{k}}{K_{t-1}}-\delta_{k}\right)^{2} K_{t-1}, \\
1 & =\lambda_{t}^{k}\left[1-\phi_{k}\left(\frac{I_{t}^{k}}{K_{t-1}}-\delta_{k}\right)\right], \\
S_{t} & =\left(D_{t-1}^{\frac{\xi-1}{\xi}}+\kappa_{3} O_{t}^{h}\right)^{\frac{\xi-1}{\xi}}, \\
W_{t} & =Y_{t}^{\frac{\xi}{\sigma-1}}\left[\left(A_{t} L_{t}\right)^{\alpha}\left(K_{t-1}\right)^{1-\alpha}\right]^{\frac{\sigma-1}{\sigma}} L_{t}^{-1}, \\
r_{t} & =(1-\alpha) Y_{t}^{\frac{1}{\sigma}}\left[\left(A_{t} L_{t}\right)^{\alpha}\left(K_{t-1}\right)^{1-\alpha}\right]^{\frac{\sigma-1}{\sigma}} K_{t-1}^{-1}, \\
P_{t}^{o} & =Y_{t}^{\frac{1}{\sigma}} a_{1}\left(O_{t}^{f}\right)^{-\frac{1}{\sigma}}, \\
Y_{t} & =\left\{\left[\left(A_{t} L_{t}\right)^{\alpha}\left(K_{t-1}\right)^{1-\alpha}\right]^{\frac{\sigma-1}{\sigma}}+a_{1}\left(O_{t}^{f}\right)^{\frac{\sigma-1}{\sigma}}\right\}^{\frac{\sigma}{\sigma-1}}, \\
Y_{t} & =C_{t}+I_{t}^{k}+I_{t}^{d}+P_{t}^{o} O_{t}^{h}+P_{t}^{o} O_{t}^{f} .
\end{aligned}
$$

where $b=\frac{\nu-1}{\nu}, w=1-\frac{1}{\tau}, \lambda_{t}$ and $\lambda_{t}^{k}$ are the Lagrange multipliers associated with constraints 7 and 9 respectively.

\subsection{Putty Clay Model Without Durable Investment}

We solve the model following the procedure of Atkeson and Kehoe (1999). That is, we impose that (1) all types of existing capital are fully utilized and (2) investment at time $t$ occurs in one type of physical capital. We present here evidence that these assumptions are valid. The argument closely follows the argument and derivations in Atkeson and Kehoe 
(1999), and we refer the interested reader to the details in their paper.

Consider the problem for the firm that must choose its labor services and decide its energy usage for an existing capital stock. That is, consider the problem,

$$
\begin{aligned}
& \max _{e_{t}^{f}(v), L_{t}} A_{t}\left(\int_{v} e_{t}^{f}(v) v^{\varphi} d v\right)^{1-\alpha} L_{t}^{\alpha}-W_{t} L_{t}-P_{t}^{o} \int_{v} e_{t}^{f}(v) d v \\
& \text { subject to } \frac{K_{t-1}(v)}{v} \geq e_{t}^{f}(v), \text { and } e_{t}^{f}(v) \geq 0 .
\end{aligned}
$$

Let $\mu_{t}(v)$ and $\chi_{t}(v)$, respectively, be the Lagrange multipliers on the constraints. The first order conditions are

$$
\begin{aligned}
& (1-\alpha) A_{t} z_{t-1}^{-\alpha} L_{t}^{\alpha} v^{\varphi}-P_{t}^{o}=\mu_{t}(v) v-\chi_{t}(v) \\
& \alpha A_{t} z_{t-1}^{1-\alpha} L_{t}^{\alpha-1}-W_{t}=0
\end{aligned}
$$

where $z_{t-1}=\int_{v} e_{t}^{f}(v) v^{\varphi} d v$. When $K_{t-1}(v)>0, \chi_{t}(v)=0$ if $\mu_{t}(v)>0$, and $\mu_{t}(v)=0$ if $\chi_{t}(v)>0$. This, along with the condition that the Lagrange multipliers are nonnegative, leads to the condition

$$
\mu_{t}(v) v=\max \left[(1-\alpha) A_{t} z_{t-1}^{-\alpha}\left(L_{t}(A, z, W)\right)^{\alpha} v^{\varphi}-P_{t}^{o}, 0\right]
$$

This gives us a cut-off type of energy intensity, $v^{*}$, that satisfies

$$
(1-\alpha) A_{t} z_{t-1}^{-\alpha}\left(L_{t}(A, z, W)\right)^{\alpha} v^{\varphi}-P_{t}^{o}=0 .
$$

For any existing capital of type $v>v^{*}$, capital is fully utilized. For any existing capital of type $v<v^{*}$, capital is left idle.

Consider now the restricted model where capital is assumed to be fully utilized. In this case, aggregate capital services and oil usage evolve according to

$$
\begin{aligned}
z_{t} & \leq\left(1-\delta_{k}\right) z_{t-1}+\int_{v} I_{t}^{k}(v) \frac{v^{\varphi}}{v} d v \\
O_{t}^{f} & \geq\left(1-\delta_{k}\right) O_{t-1}^{f}+\int_{v} \frac{I_{t}^{k}(v)}{v} d v \\
I_{t}^{k}(v) & \geq 0 \forall v \in V
\end{aligned}
$$

From the solution to this restricted model, we can determine $e_{t}^{f}(v)$ and $K_{t}(v)$ from the conditions: $e_{t}^{f}(v)=K_{t-1}(v) / v$ and $I_{t}^{k}(v)=K_{t}(v)-\left(1-\delta_{k}\right) K_{t-1}(v)$. As long as $v>v_{t}^{*}$ for all $v$ satisfying $K_{t-1}(v)>0$, this solution is an equilibrium of the original model. Furthermore, the 
solution will lead to positive investment in only one type of capital (see the proof in Atkeson and Kehoe (1999)), validating our second imposed constraint for the solution procedure.

Figure 8 plots $v_{t}$ and $v_{t}^{*}$ from a model simulation over 10,000 periods using our calibrations and a third order approximation of the model. In almost all cases, $v>v^{*}$ for all $t$, suggesting that the assumption that capital is fully utilized is satisfied for most of the support of the shock processes. Notice that in only 1 period for the $\tau=3$ simulation is this assumption violated.

The equilibrium conditions for the model are

$$
\begin{aligned}
Y_{t} & =A_{t} L_{t}^{\alpha} z_{t-1}^{1-\alpha} \\
z_{t} & =\left(1-\delta_{k}\right) z_{t-1}+\frac{I_{t}^{k}}{v_{t}} v_{t}^{\varphi} \\
O_{t}^{f} & =\left(1-\delta_{k}\right) O_{t-1}^{f}+\frac{I_{t}^{k}}{v_{t}} \\
Y_{t} & =C_{t}+I_{t}^{k}+P_{t}^{o} O_{t-1}^{f} \\
\lambda_{t} & =C_{t}^{-\frac{1}{\tau}} \\
0 & =\alpha \lambda_{t} \frac{Y_{t}}{L_{t}}-\kappa_{2} L_{t}^{\frac{1}{\mu}} \\
\lambda_{t}^{z} & =\beta E_{t}\left[\lambda_{t+1}(1-\alpha) \frac{Y_{t+1}}{z_{t}}+(1-\delta) \lambda_{t+1}^{z}\right] \\
\lambda_{t}^{f} & =\beta E_{t}\left[\lambda_{t+1} P_{t+1}^{o}+(1-\delta) \lambda_{t+1}^{f}\right] \\
\lambda_{t} & =\lambda_{t}^{z}\left[v_{t}^{\varphi-1}-\frac{\lambda_{t}^{f}}{v_{t}}\right] \\
0 & =\lambda_{t}^{f} v_{t}^{-2}+\lambda_{t}^{z}(\varphi-1) v_{t}^{\varphi-2} \\
P_{t}^{o} & =(1-\alpha) A_{t} z_{t-1}^{-\alpha} L_{t}^{\alpha}\left(v_{t}^{*}\right)^{\varphi}
\end{aligned}
$$

where $\lambda_{t}$ is the Lagrange multiplier on the resource constraint and $\lambda_{t}^{z}$ and $\lambda_{t}^{f}$ are the Lagrange multipliers associated with constraints 15 and 16 respectively.

\subsection{Putty Clay Model With Durable Investment}

To solve the model, we impose that (1) all types of existing capital and durables are fully utilized and (2) capital and durable investment at time $t$ occurs in one type of physical capital and durable good. We present here evidence that these assumptions are valid. We focus on the assumptions for durables, as the assumptions for capital goods are discussed in section 2.2 .

Consider the household's decision for energy usage for existing durables. That is, consider 

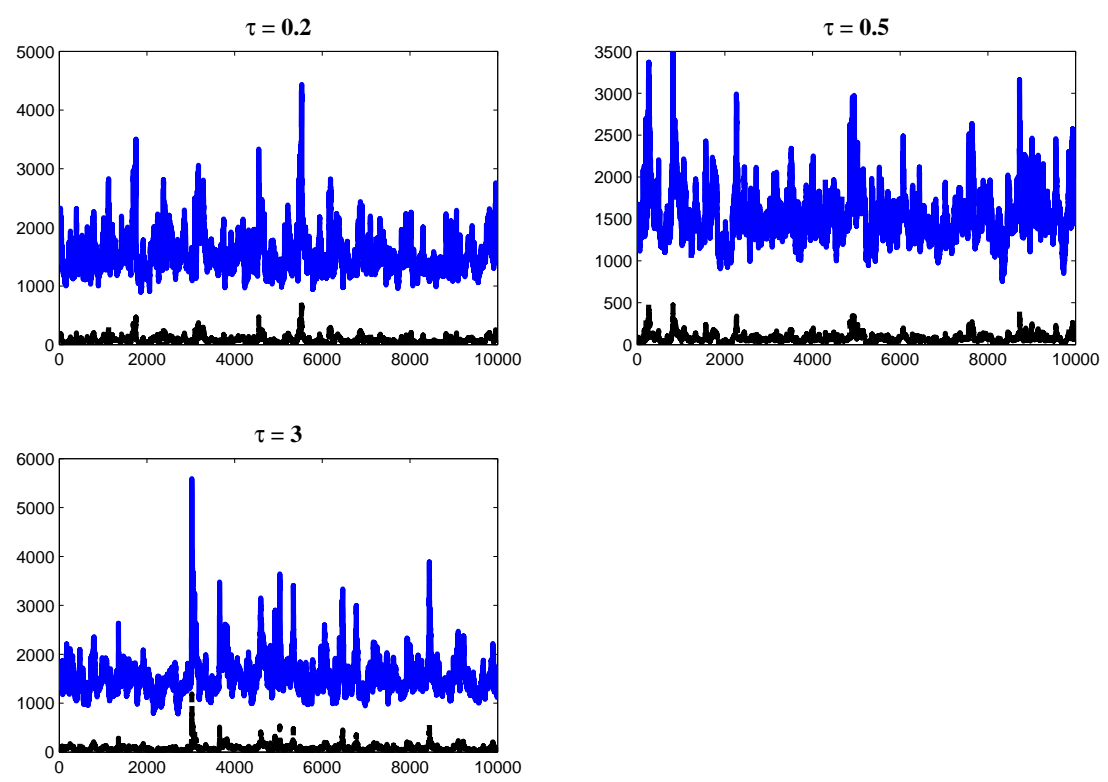

Figure 8: Energy intensity of new capital (blue solid line) and the cut-off energy intensity (black solid line). Simulation from putty-clay model without durable investment, starting from the stochastic steady state.

the problem,

$$
\begin{aligned}
& \max _{e_{t}^{h}\left(v^{d}\right)} \frac{\left[C_{t}^{\frac{\nu-1}{\nu}}+\kappa_{1}\left(\int_{v^{d}} e_{t}^{h}\left(v^{d}\right)\left(v^{d}\right)^{\varphi^{d}} d v^{d}\right)^{\frac{\nu-1}{\nu}}\right]^{\frac{1-\frac{1}{\tau}}{\nu}}}{1-\frac{1}{\tau}} \\
& \text { subject to } \frac{D_{t-1}(v)}{v} \geq e_{t}^{h}(v), \text { and } e_{t}^{h}(v) \geq 0 \\
& \text { and } C_{t}+P_{t}^{o} \int_{v} e_{t}^{h}(v) d v \leq \bar{I}
\end{aligned}
$$

where $\bar{I}$ is income after allocations for investment. Let $\mu_{t}^{h}(v), \chi_{t}^{h}(v)$, and $\lambda_{t}^{h}$, respectively, be the Lagrange multipliers on the constraints. The first order condition is

$$
U_{d}\left(v^{d}\right)^{\varphi^{d}}-U_{c} P_{t}^{o}=\mu_{t}^{h}\left(v^{d}\right) v^{d}-\chi_{t}^{h}\left(v^{d}\right)
$$

where $U_{d}$ and $U_{c}$ are the marginal utilities with respect to durables and consumption. When $D_{t-1}\left(v^{d}\right)>0, \chi_{t}^{h}\left(v^{d}\right)=0$ if $\mu_{t}^{h}\left(v^{d}\right)>0$, and $\mu_{t}^{h}\left(v^{d}\right)=0$ if $\chi_{t}^{h}\left(v^{d}\right)>0$. This, along with the condition that the Lagrange multipliers are nonnegative, leads to the condition

$$
\mu_{t}^{h}\left(v^{d}\right) v^{d}=\max \left[U_{d}\left(v^{d}\right)^{\varphi^{d}}-U_{c} P_{t}^{o}, 0\right]
$$


This gives us a cut-off type of energy intensity, $v^{d *}$, that satisfies

$$
\kappa_{1} D_{t-1}^{-\frac{1}{\nu}}\left(v^{d *}\right)^{\varphi^{d}}=C_{t}^{-\frac{1}{\nu}} P_{t}^{o} .
$$

where $D_{t-1}=\int_{v^{d}} e_{t}^{h}\left(v^{d}\right)^{\varphi} d v^{d}$. For any existing durable good of type $v^{d}>v^{d *}$, the good is fully utilized. For any existing durable of type $v^{d}<v^{d *}$, the good is left idle.

Consider now the restricted model where durables are fully utilized by assumption. In this case, aggregate durable services and household oil usage evolve according to

$$
\begin{aligned}
D_{t} & \leq\left(1-\delta_{d}\right) D_{t-1}+\int_{v}^{d} I_{t}^{d}\left(v^{d}\right) \frac{\left(v^{d}\right)^{\varphi^{d}}}{v^{d}} d v^{d} \\
O_{t}^{h} & \geq\left(1-\delta_{d}\right) O_{t-1}^{h}+\int_{v}^{d} \frac{I_{t}^{d}\left(v^{d}\right)}{v^{d}} d v^{d} \\
I_{t}^{d}(v) & \geq 0 \forall v^{d} \in V^{d}
\end{aligned}
$$

From the solution to this restricted model, we can determine $e_{t}^{h}\left(v^{d}\right)$ and $D_{t}\left(v^{d}\right)$ from the conditions: $e_{t}^{h}\left(v^{d}\right)=D_{t-1}\left(v^{d}\right) / v^{d}$ and $I_{t}^{d}\left(v^{d}\right)=D_{t}\left(v^{d}\right)-\left(1-\delta_{d}\right) D_{t-1}\left(v^{d}\right)$. As long as $v^{d}>v_{t}^{d *}$ for all $v^{d}$ satisfying $D_{t-1}\left(v^{d}\right)>0$, this solution is an equilibrium of the original model.

Furthermore, the solution will lead to positive investment in only one type of durables, validating our second imposed constraint for the solution procedure. We can see this from the first order condition for $I_{t}^{d}\left(v^{d}\right)$, which is

$$
\lambda_{t}^{i}\left(v^{d}\right)=\lambda_{t}-\lambda_{t}^{d}\left(v_{t}^{d}\right)^{\varphi^{d}-1}+\lambda_{t}^{h} / v_{t}^{d}
$$

where $\lambda_{t}$ is the Lagrange multiplier from the resource constraint and $\lambda_{t}^{d}, \lambda_{t}^{h}$, and $\lambda_{t}^{i}$ are the Lagrange multipliers associated with equations (22), (23), and (24). $I_{t}^{d}\left(v^{d}\right)>0$ if $\lambda_{t}^{i}\left(v^{d}\right)=0$. Since $\lambda_{t}^{i}\left(v^{d}\right)$ cannot be negative, this implies zero is its minimum value. Furthermore, the minimum is achieved for a unique $v^{d}$; specifically the $v^{d}$ that solves

$$
\frac{\lambda_{t}^{d}\left(1-\varphi^{d}\right)\left(v^{d}\right)^{\varphi^{d}}}{\left(v^{d}\right)^{2}}-\frac{\lambda_{t}^{h}}{\left(v^{d}\right)^{2}}=0
$$

Since $\lambda_{t}^{i}\left(v^{d}\right)$ has a unique minimum, there is only one type $v^{d}$ for which $I_{t}^{d}\left(v^{d}\right)>0$.

Figure 9 plots $v_{t}, v_{t}^{d}, v_{t}^{*}$ and $v_{t}^{d *}$ from a model simulation over 10,000 periods using our calibrations and a third order approximation of the model. In all cases, $v>v^{*}$ and $v^{d}>v^{d *}$ for all $t$, suggesting that the assumption that capital and durables are fully utilized is satisfied for most of the support of the shock processes. 

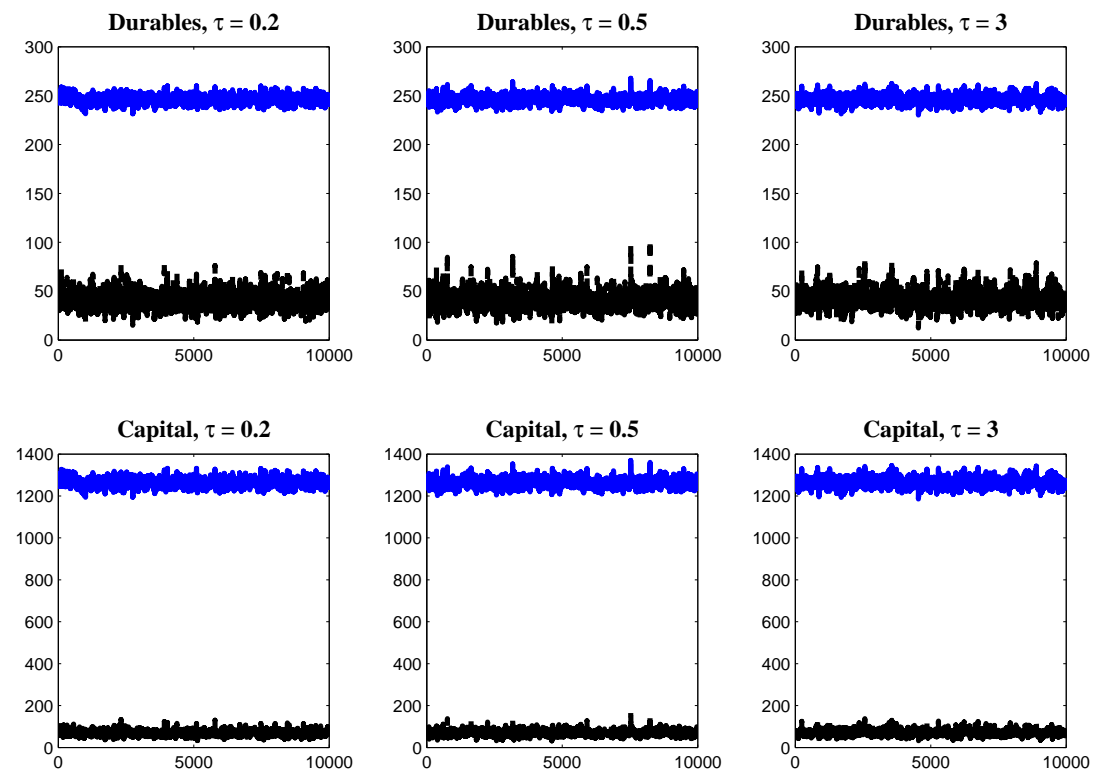

Figure 9: Energy intensity of new capital and durables (blue solid line) and the cut-off energy intensity (black solid line). Simulation from putty-clay model with durable investment, starting from the stochastic steady state. 
The equilibrium conditions for the model are

$$
\begin{aligned}
& Y_{t}=A_{t} L_{t}^{\alpha} z_{t-1}^{1-\alpha} \\
& z_{t}=\left(1-\delta_{k}\right) z_{t-1}+\frac{I_{t}^{k}}{v_{t}} v_{t}^{\varphi} \\
& O_{t}^{f}=\left(1-\delta_{k}\right) O_{t-1}^{f}+\frac{I_{t}^{k}}{v_{t}} \\
& D_{t}=\left(1-\delta_{d}\right) D_{t-1}+\frac{I_{t}^{d}}{v_{t}^{d}}\left(v_{t}^{d}\right)^{\varphi^{d}} \\
& O_{t}^{h}=\left(1-\delta_{d}\right) O_{t-1}^{h}+\frac{I_{t}^{d}}{v_{t}^{d}} \\
& Y_{t}=C_{t}+I_{t}^{k}+I_{t}^{d}+P_{t}^{o} O_{t-1}^{f}+P_{t}^{o} O_{t-1}^{h} \\
& \lambda_{t}=\left[C_{t}^{b}+\kappa_{1} D_{t-1}^{b}\right]^{\frac{w}{b}-1} C_{t}^{b-1} \text {, } \\
& \lambda_{t}^{h}=\beta E_{t}\left[\lambda_{t+1} P_{t+1}^{o}+\left(1-\delta_{d}\right) \lambda_{t+1}^{h}\right] \text {, } \\
& \lambda_{t}^{d}=\beta E_{t}\left\{\lambda_{t+1}^{d}\left(1-\delta_{d}\right)+\left[C_{t+1}^{b}+\kappa_{1} D_{t}^{b}\right]^{\frac{w}{b}-1} \kappa_{1} D_{t}^{-\frac{1}{\nu}}\right\} \text {, } \\
& 0=\alpha \lambda_{t} \frac{Y_{t}}{L_{t}}-\kappa_{2} L_{t}^{\mu} \\
& \lambda_{t}^{z}=\beta E_{t}\left[\lambda_{t+1}(1-\alpha) \frac{Y_{t+1}}{z_{t}}+\left(1-\delta_{k}\right) \lambda_{t+1}^{z}\right] \\
& \lambda_{t}^{f}=\beta E_{t}\left[\lambda_{t+1} P_{t+1}^{o}+\left(1-\delta_{k}\right) \lambda_{t+1}^{f}\right] \\
& \lambda_{t}=\lambda_{t}^{z}\left[v_{t}^{\varphi-1}-\frac{\lambda_{t}^{f}}{v_{t}}\right] \\
& 0=\lambda_{t}^{f} v_{t}^{-2}+\lambda_{t}^{z}(\varphi-1) v_{t}^{\varphi-2} \\
& \lambda_{t}=\lambda_{t}^{d}\left[\left(v_{t}^{d}\right)^{\varphi^{d}-1}-\frac{\lambda_{t}^{h}}{v_{t}^{d}}\right] \\
& 0=\lambda_{t}^{h}\left(v_{t}^{d}\right)^{-2}+\lambda_{t}^{d}\left(\varphi^{d}-1\right)\left(v_{t}^{d}\right)^{\varphi^{d}-2} \\
& P_{t}^{o}=(1-\alpha) A_{t} z_{t-1}^{-\alpha} L_{t}^{\alpha}\left(v_{t}^{*}\right)^{\varphi} \\
& P_{t}^{o}=\kappa_{1} D_{t-1}^{-\frac{1}{\nu}} C_{t}^{\frac{1}{\nu}}\left(v_{t}^{d *}\right)^{\varphi^{d}}
\end{aligned}
$$

where $b=\frac{\nu-1}{\nu}, w=1-\frac{1}{\tau}, \lambda_{t}$ is the Lagrange multiplier on the resource constraint and $\lambda_{t}^{z}, \lambda_{t}^{f}, \lambda_{t}^{d}, \lambda_{t}^{h}$ are the Lagrange multipliers associated with constraints 15, 16, 18, and 19 respectively. 


\section{Derivations of Edgeworth Substitutability/Complementarity}

Consider

$$
U=\frac{\left[z_{1} C^{b}+z_{2} S\left(D, O^{h}\right)^{b}\right]^{\frac{w}{b}}}{w},
$$

where $b=\frac{\nu-1}{\nu}, w=1-\frac{1}{\tau}$, and $S\left(D, O^{h}\right)$ is a CES production function that combines the durable good, $D$, and oil, $O^{h}$, to produce the service flow, $S$. For utility functions of this form it is fairly easy to show the following

$$
\begin{aligned}
U_{c} & =\left[z_{1} C^{b}+z_{2} S\left(D, O^{h}\right)^{b}\right]^{\frac{w}{b}-1} z_{1} C^{b-1}, \\
U_{s} & =\left[z_{1} C^{b}+z_{2} S\left(D, O^{h}\right)^{b}\right]^{\frac{w}{b}-1} z_{2} S^{b-1}, \\
U_{d} & =\left[z_{1} C^{b}+z_{2} S\left(D, O^{h}\right)^{b}\right]^{\frac{w}{b}-1} z_{2} S^{b-1} S_{d}, \\
U_{o} & =\left[z_{1} C^{b}+z_{2} S\left(D, O^{h}\right)^{b}\right]^{\frac{w}{b}-1} z_{2} S^{b-1} S_{o},
\end{aligned}
$$

where $U_{i}$ is just the deriative of $U$ with respect to $i$ and likewise for $S_{j}$. Working with these equations one can then show that

$$
\begin{aligned}
\frac{U_{c s} S}{U_{c}} & =\frac{\tau-\nu}{\nu \tau} \theta_{s} \\
\frac{U_{c d} D}{U_{c}} & =\frac{\tau-\nu}{\nu \tau} \theta_{s} \gamma_{d}, \\
\frac{U_{c o} O^{h}}{U_{c}} & =\frac{\tau-\nu}{\nu \tau} \theta_{s} \gamma_{o}
\end{aligned}
$$

where

$$
\begin{aligned}
\theta_{s} & =\frac{z_{2} S^{b}}{z_{1} C^{b}+z_{2} S^{b}}, \\
\gamma_{d} & =\frac{S_{d} D}{S} \\
\gamma_{o} & =\frac{S_{o} O^{h}}{S},
\end{aligned}
$$

so that $\theta_{s}$ can be interpreted as the utility share provided by $S$ and $\gamma_{d}$ and $\gamma_{o}$ can be interpreted as the share of $S$ produced using $D$ and $O^{h}$, respectively. The important result from the previous equations is that $C$ is a compliment to, independent of, or a substitute for $S, D$, and $O^{h}$, as $\tau>=<\nu$. 
Likewise, further derivations show that

$$
\begin{aligned}
\frac{U_{d o} O^{h}}{U_{d}} & =\frac{\gamma_{o}}{\xi}-\frac{\gamma_{o}}{\nu}+\frac{\tau-\nu}{\nu \tau} \theta_{s}, \\
\frac{U_{o d} D}{U_{o}} & =\frac{\gamma_{d}}{\xi}-\frac{\gamma_{d}}{\nu}+\frac{\tau-\nu}{\nu \tau} \theta_{s},
\end{aligned}
$$

which shows that the complimentarity of $D$ and $O^{h}$ depends upon the calibration of $\xi, \nu$, and $\tau$ jointly. $\xi<\nu<\tau$ is a sufficient condition for $D$ and $O^{h}$ to be Edgeworth compliments a the deterministic steady state. The opposite $\xi>\nu>\tau$ implies they are substitutes. For the case where $\xi=\nu=\tau$, the two are independent goods.

\section{References}

Abel, A. B. (1983): "Optimal Investment Under Uncertainty," American Economic Review, 73(1), 228-33.

Arnberg, S., and T. B. BJorner (2007): "Substitution between energy, capital and labour within industrial companies: A micro panel data analysis," Resource and Energy Economics, 29, 122-136.

Atkeson, A., And P. J. Kehoe (1999): "Models of Energy Use: Putty-Putty versus Putty-Clay," American Economic Review, 89(4), 1028-1043.

Atkins, F. J., And S. M. T. JazAYeri (2004): "A Literature Review of Demand Studies in World Oil Markets," University of Calgary Discussion Paper No. 2004-07.

Bachmann, R., R. J. Caballero, and E. M. Engel (2010): "Aggregate Implications of Lumpy Investment: New Evidence and a DSGE Model," NBER Working Paper No. 12336.

Bernanke, B. S. (1983): "Irreversibility, Unvertainty, and Cyclical Investment," The Quarterly Journal of Economics, 98(1), 85-106.

BLoom, N. (2009): "The Impact of Uncertainty Shocks," Econometrica, 77(3), 623-685.

Bloom, N., S. Bond, and J. V. Reenen (2007): "Uncertainty and Investment Dynamics," Review of Economic Studies, 74(2), 391-415.

Bodenstein, M., C. Erceg, and L. Guerrieri (2011): "Oil Shocks and External Adjustment," Journal of International Economics, 83(1), 168-184. 
Born, B., And J. Pfeifer (2011): "Policy Rish and the Business Cycle," Bonn Econ Discussion Paper 06/2011.

Breusch, T. S., and A. R. Pagan (1979): "A Simple Test for Hesteroscedasticity and Random Coefficient Variation," Econometrica, 47(5), 1287-1294.

Caballero, R. J. (1991): "On the Sign of the Investment-Uncertainty Relationship," American Economic Review, 81, 279-288.

Carroll, C. D., and M. S. Kimball (2008): "Precautionary Saving and Precautionary Wealth," in The New Palgrave Dictionary of Economics, ed. by S. N. Durlauf, and L. E. Blume. Palgrave Macmillan, second edn.

Doucet, A., N. de Freitas, and N. Gordon (2001): Sequential Monte Carlo Methods in Practice. Springer-Verlag, New York.

Elder, J., And A. Serletis (2010): "Oil Price Uncertainty," Journal of Money, Credit and Banking, 42(6), 1137-1159.

Ferderer, J. (1996): "Oil Price Volatility and the Macroeconomy," Journal of Macroeconomics, 18(1), 1-26.

Fernandez-Villaverde, J., P. A. Guerron-Quintana, K. Kuester, and J. RubioRamirez (2011): "Fiscal Volatility Shocks and Economic Activity," National Bureau of Economic Research Working Paper No. 17317.

Fernandez-Villaverde, J., P. A. Guerron-Quintana, J. F. Rubio-Ramirez, and M. Uribe (2011): "Risk Matters: The Real Effects of Stochastic Volatility Shocks," American Economic Review, 101(6), 2530-2561.

Gilchrist, S., and J. C. Williams (2005): "Investment, Capacity, and Uncertainty: A Putty-Clay Approach," Review of Economic Dynamics, 8(1), 1-27.

Guo, H., and K. L. Kliesen (2005): "Oil Price Volatility and U.S. Macroeconomic Activity," Federal Reserve Bank of St. Louis Review, 87(6), 669-683.

Guvenen, F. (2006): "Reconciling Conflicting Evidence on the Elasticity of Intertemporal Substitution: A Macroeconomic Perspective," Journal of Monetary Economics, 53(7), $1451-72$.

Hartman, R. (1972): "The Effects of Price and Cost Uncertainty on Investment," Journal of Economic Theory, 5(2), 258-266. 
Hughes, J., C. Knittel, and D. Sperling (2008): "Evidence of a Shift in the Short-Run Price Elasticity of Gasoline Demand," Energy Journal, 29(1), 113-134.

Jones, D., P. Leiby, and I. Paik (2004): "Oil Price Shocks and the Macroeconomy: What Has Been Learned Since 1996?," Energy Journal, 25(2), 1-32.

KellogG, R. (2010): "The Effect of Uncertainty on Investment: Evidence from Texas Oil Drilling," NBER Working Paper 16541.

Khan, A., and J. Thomas (2008): "Idiosyncratic Shocks and the Role of Nonconvexities in Plant and Aggregate Investment Dynamics," Econometrica, 76(2), 395-436.

Kilian, L. (2008): "The Economic Effects of Energy Price Shocks," Journal of Economic Literature, 46(4), 871-909.

(2009): "Not All Oil Price Shocks Are Alike: Disentangling Demand and Supply Shocks in the Crude Oil Market," American Economic Review, 99(3), 1053-69.

Koenker, R. (1981): "A Note on Studentizing a Test for Heteroscedasticity," Journal of Econometrics, 17(1), 107-112.

PinDyCK, R. (1991): "Irreversibility, Uncertainty and Investment," Journal of Economic Literature, 29(3), 1110-1148.

Pindyck, R. S., and J. J. Rotemberg (1983): "Dynamic Factor Demands and the Effects of Energy Price Shocks," American Economic Review, 73(5), 1066-1079.

Plante, M. (2009): "How Should Monetary Policy Respond to Exogenous Changes in the Relative Price of Oil?," CAEPR Working Paper No. 2009-013.

Sandmo, A. (1970): "The Effect of Uncertainty on Saving Decisions," Review of Economic Studies, 37(3), 353-360.

Schmitt-Grohe, S., And M. URIBe (2004): "Solving dynamic general equilibrium models using a second-order approximation to the policy function," Journal of Economic Dynamics and Control, 28, 755-775.

Stock, J. H., And M. W. Watson (1999): "Forecasting Inflation," Journal of Monetary Economics, 44(2), 293-335.

Stockman, D. R. (2006): "Oil Shocks and Macroeconomic Activity: A Putty-Clay Perspective," University of Delaware Working Paper No. 2006-15. 
Swanson, E., G. Anderson, and A. Levin (2005): "Higher-Order Perturbation Solutions to Dynamic, Discrete-Time Rational Expectations Models," Working Paper.

Thomas, J. (2002): "Is Lumpy Investment Relevant for the Business Cycle?," Journal of Political Economy, 110(3), 508-534.

Veracierto, M. L. (2002): "Plant-Level Irreversible Investment and Equilibrium Business Cycles," American Economic Review, 92(1), 181-197.

Wei, C. (2003): "Energy, the Stock Market, and the Putty-Clay Investment Model," American Economic Review, 93(1), 311-323.

- (2009): "A Dynamic General Equilibrium Model of Driving, Gasoline Use and Vehicle Fuel Efficiency," George Washington University manuscript.

White, H. (1980): "A Heteroskedasticity-Consistent Covariance Matrix Estimator and a Direct Test for Heteroskedasticity," Econometrica, 48(4), 817-838.

Wooldridge, J. M. (1990): "A Unified Approach to Robust, Regression-Based Specification Tests," Econometric Theory, 6(1), 17-43. 